\title{
Delayed Activation of Spinal Microglia Contributes to the Maintenance of Bone Cancer Pain in Female Wistar Rats via P2X7 Receptor and IL-18
}

\author{
Yan Yang (杨艳), ${ }^{1 *}$ Hui Li (李卉), ${ }^{1 *}$ Ting-Ting Li (李婷婷), ${ }^{1}$ Hao Luo (罗浩), ${ }^{1}$ Xi-Yao Gu (顾希圭), ${ }^{1}$ Ning Lü (吕宁), ${ }^{1}$ \\ Ru-Rong Ji, ${ }^{2}$ and Yu-Qiu Zhang (张玉秋) ${ }^{1}$ \\ ${ }^{1}$ Institute of Neurobiology, Institutes of Brain Science and State Key Laboratory of Medical Neurobiology, Collaborative Innovation Center for Brain \\ Science, Fudan University, Shanghai 200032, People's Republic of China, and ${ }^{2}$ Departments of Anesthesiology and Neurobiology, Duke University Medical \\ Center, Durham, North Carolina 27710
}

Accumulating evidence suggests that activation of spinal microglia contributes to the development of inflammatory and neuropathic pain. However, the role of spinal microglia in the maintenance of chronic pain remains controversial. Bone cancer pain shares features of inflammatory and neuropathic pain, but the temporal activation of microglia and astrocytes in this model is not well defined. Here, we report an unconventional role of spinal microglia in the maintenance of advanced-phase bone cancer pain in a female rat model. Bone cancer elicited delayed and persistent microglial activation in the spinal dorsal horn on days 14 and 21, but not on day 7 . In contrast, bone cancer induced rapid and persistent astrocytic activation on days 7-21. Spinal inhibition of microglia by minocycline at $14 \mathrm{~d}$ effectively reduced bone cancer-induced allodynia and hyperalgesia. However, pretreatment of minocycline in the first week did not affect the development of cancer pain. Bone cancer increased ATP levels in CSF, and upregulated P2X7 receptor, phosphorylated p38, and IL-18 in spinal microglia. Spinal inhibition of $\mathrm{P} 2 \mathrm{X} 7 / \mathrm{p}-38 / \mathrm{IL}-18$ pathway reduced advanced-phase bone cancer pain and suppressed hyperactivity of spinal wide dynamic range (WDR) neurons. IL-18 induced allodynia and hyperalgesia after intrathecal injection, elicited mechanical hyperactivity of WDR neurons in vivo, and increased the frequency of mEPSCs in spinal lamina IIo nociceptive synapses in spinal cord slices. Together, our findings demonstrate a novel role of microglia in maintaining advanced phase cancer pain in females via producing the proinflammatory cytokine IL-18 to enhance synaptic transmission of spinal cord nociceptive neurons.

Key words: bone cancer pain; female rats; IL-18; microglia; neuron-glial interaction; P2X7 receptor

\section{Introduction}

Bone cancer-induced pain is one of the most severe types of chronic pain. Approximately $90 \%$ of advanced bone cancer patients must cope with chronic pain syndromes related to tumor progression and failed treatment (Mantyh, 2006; Colvin and Fallon, 2008). Despite decades of basic and clinical research, the exact cellular and molecular mechanisms of cancer-induced pain remain elusive, and there is a pressing need for more effective pharmacological treatment for cancer pain.

Activation of spinal microglia [e.g., microgliosis, as indicated by morphological changes of microglia and upregulations of mi-

\footnotetext{
Received Dec. 25, 2014; revised April 7, 2015; accepted April 17, 2015.

Author contributions: R.-R.J. and Y.-Q.Z. designed research; Y.Y., H. Li, T.-T.L., H. Luo, X.-Y.G., N.L., and Y.-Q.Z. performed research; Y.Y., H. Li, R.-R.J., and Y.-Q.Z. analyzed data; Y.Y., R.-R.J., and Y.-Q.Z. wrote the paper.

This research was supported by the National Natural Science Foundation of China (Grants 31420103903, 31421091, 31271183, and 81471130) and the National Basic Research Program of China (Grant 2013CB531900).

*Y.Y. and H. Li contributed equally to this work.

The authors declare no competing financial interests.

Correspondence should be addressed to either of the following: Dr. Yu-Qiu Zhang, Institute of Neurobiology, Fudan University, 1202 Mingdao Building, 131 Dong An Road, Shanghai 200032, People's Republic of China, E-mail: yuqiuzhang@fudan.edu.cn; or Ru-Rong Ji, Departments of Anesthesiology and Neurobiology, Duke University Medical Center, Durham, NC 27710, E-mail: ru-rong.ji@duke.edu.

DOI:10.1523/JNEUROSCI.5250-14.2015

Copyright $\odot 2015$ the authors $\quad 0270-6474 / 15 / 357950-14 \$ 15.00 / 0$
}

croglial markers such as $\mathrm{CD}-11 \mathrm{~b}$ or ionized calcium binding adapter molecule-1 (IBA-1)] is a common phenomenon in nerve injury-induced neuropathic pain (Suter et al., 2007) and also occurs in some inflammatory pain conditions (Shan et al., 2007). Compared with rapid microglial activation, nerve injury induces delayed but more persistent astrocyte activation (e.g., astrogliosis, as indicated by morphological changes of astrocytes and upregulations of astrocyte markers such as GFAP and S100) (Tanga et al., 2004; Ji et al., 2013). In particular, the blockade of microglial activation only reduced neuropathic and inflammatory pain in the early phase (Milligan et al., 2003; Raghavendra et al., 2003). Therefore, it was believed that microglia and astrocytes, respectively, contribute to the development and maintenance of chronic pain (Shan et al., 2007; Cao and Zhang, 2008; Sun et al., 2008; Ji et al., 2013). Notably, the role of microglia in cancer pain is highly controversial, and there is a large variation in spinal microglial activation due to differences in sexes, species/strains, and origins of tumor cells (Medhurst et al., 2002; Zhang et al., 2005; Hald et al., 2009; Ducourneau et al., 2014). Spinal cord autopsy from patients with pancreatic cancer pain showed enlarged areas of GFAP and IBA-1 immunoreactivities, suggesting long-lasting activation of spinal microglia and astrocytes in human cancer pain (Imoto et al., 2012), but spinal cord autopsy 
Table 1. Numbers of rats used in different experiments

\begin{tabular}{llclr}
\hline Experiment & Sample size & Groups $(n)$ & Samples $(n)$ & Rats $(n)$ \\
\hline Behavioral test & $6-12$ rats & 29 & 235 rats & 235 \\
TdT-Fluor apoptosis & $2-4$ rats & 4 & 12 rats & 12 \\
Immunohistochemistry & $4-6$ rats & 13 & 55 rats & 55 \\
Western blot & $4-8$ rats & 15 & 60 rats & 60 \\
ATP measure in CSF & $4-6$ rats & 2 & 10 rats & 10 \\
Extracellular recording & $6-25$ neurons & 7 & 111 neurons & 69 \\
Patch-clamp recording & $8-10$ neurons & 4 & 30 neurons & 20 \\
Total number of rats & & & & 461 \\
\hline
\end{tabular}

A total of 461 female Wistar rats were used in this study.

from patients with HIV-associated neuropathic pain only exhibited long-lasting activation of astrocytes (Shi et al., 2012).

ATP plays an important role in microglia activation in the CNS (He et al., 2012; Trang et al., 2012). Nerve injury induces $\mathrm{P} 2 \mathrm{X} 4$ upregulation in spinal microglia to drive neuropathic pain via activation of p38 MAPK and secretion of BDNF (Tsuda et al., 2003; Trang et al., 2009). Microglia also express P2X7 receptor (P2X7R; Tsuda et al., 2003; Zhou et al., 2010), which controls the release of proinflammatory cytokines (Solle et al., 2001; Inoue, 2007). P2X7R-deficient mice exhibited reduced neuropathic pain and inflammatory pain (Chessell et al., 2005). Interestingly, Hansen et al. (2011) reported no impairment of bone cancer pain in P2X7R knock-out mice. However, the distinct role of spinal P2X7R was not examined in this study. In the present study, using a female rat model of bone cancer pain, we observed delayed and persistent activation of spinal microglia that occurs after astrocytic activation, and the inhibition of microglia significantly reduced the established cancer pain in the advanced phase. We also found that microglia sustain cancer pain via P2X7R-triggered upregulation of the proinflammatory cytokine interleukin-18 (IL-18) to drive hyperactivity and central sensitization in spinal cord neurons.

\section{Materials and Methods}

Experimental animals. Adult (2- to 3-month-old) and young (2- to 3 -week-old) female Wistar rats were obtained from Shanghai Experimental Animal Center of Chinese Academy of Sciences and were housed under a $12 \mathrm{~h}$ light/dark cycle with food and water available ad libitum. A total of 461 rats were used for in vivo and in vitro studies (Table 1). All experiments were approved by the Animal Care and Use Committee of Fudan University and followed the policies issued by the guidelines for pain research of the International Association for the Study of Pain. All of the following behavioral testing, quantification of Western blots, and immunohistochemical experiments described herein were performed by experimenters who were blind to the treatments.

Model of bone cancer pain. Tumor cells were extracted from the cancerous ascitic fluid of rats that received intraperitoneal (i.p.) inoculation of Walker 256 rat mammary gland carcinoma cells. Suspensions of $1 \times$ $10^{8} / \mathrm{ml}$ tumor cells in PBS were prepared. The inoculation was performed as previously described (Xu et al., 2013). Briefly, rats were anesthetized with sodium pentobarbital $(50 \mathrm{mg} / \mathrm{kg}$, i.p.). The right leg was shaved, and the skin was disinfected with iodine tincture and 75\% ethanol. A 22 gauge needle was inserted at the site of the intercondylar eminence of the right tibia and was then replaced with a $10 \mu \mathrm{l}$ microinjection syringe containing a $4 \mu \mathrm{l}$ suspension of tumor cells $\left(4 \times 10^{5}\right)$. The contents of the syringe were slowly injected into the tibial cavity. To prevent the leakage of cells outside the bone, the injection site was sealed with bone wax. For the sham group (controls), $4 \mu$ l of PBS was injected instead of carcinoma cells into the tibia. At the end of the experiment, radiological, postmortem, and histological evaluations were performed. Rats that showed no obvious tumor growth and bone destruction after the inoculation of tumor cells were excluded from the experiments.
Drugs and administration. The inhibitor of microglial activation minocycline (Sigma-Aldrich), astrocyte metabolic inhibitor fluorocitrate (Sigma-Aldrich), P2X7 antagonist brilliant blue G (BBG; SigmaAldrich), recombinant human IL-18 binding protein [IL-18BP (an inhibitor of IL-18 activity); R\&D Systems], and recombinant rat IL-18 (R\&D Systems) were dissolved and diluted in sterile PBS. The specific p38 inhibitor SB239063 (Tocris Bioscience) was dissolved in 10\% DMSO. Small interfering RNA (siRNA) targeting the rat P2X7R mRNA (L-091415-00-0020) or nontargeting control siRNA (D-001220-01-20; Thermo Fisher Scientific) was mixed with polyethylenimine (PEI; $1.8 \mu \mathrm{l}$ of $10 \mathrm{~mm} \mathrm{PEI} / \mu \mathrm{g}$ RNA; Sigma-Aldrich), as we previously demonstrated (Kawasaki et al., 2008). To determine the temporal profile of siRNA uptake into the lumbar spinal dorsal horn, fluorescence-labeled control siRNA was intrathecally injected. Strong fluorescence was observed in the spinal dorsal horn 7-14 d after the siRNA injection. The dosages of drugs were selected based on previous reports and our preliminary studies.

For intrathecal injection, an intrathecal catheter (PE-10 tube) was inserted through the gap between the L4 and L5 vertebrae and extended to the subarachnoid space of the lumbar enlargement (L4 and L5 segments) under sodium pentobarbital anesthesia. Rats that showed any surgery-related neurological deficits were excluded from the experiment. The location of the distal end of the intrathecal catheter was verified at the end of each experiment by the injection of Pontamine sky blue via the intrathecal catheter.

Behavioral test. Mechanical allodynia was assessed by measuring paw withdrawal thresholds (PWTs) in response to a calibrated series of von Frey hairs (Stoelting Company). Rats were put in Plexiglas chambers on an elevated wire-mesh floor, and a series of von Frey hairs was applied to the plantar surface of the hindpaw in ascending order $(1,1.4,2,4,6,8,10$, and $15 \mathrm{~g}$; Stoelting Company) with a sufficient force to bend the hair for $5 \mathrm{~s}$ or until paw withdrawal. The PWT was defined as the lowest force (in grams) that produced at least three withdrawal responses in five consecutive applications.

Thermal hyperalgesia was assessed by measuring the paw withdrawal latencies (PWLs) in response to a radiant heat source using Hargreaves' test. Rats were put in Plexiglas chambers on an elevated glass platform. Heat was delivered to the glabrous surface of the paw through the glass plate using a radiant heat source (IITC Life Science). The time from the onset of radiant heat application to the withdrawal of the hindpaw was defined as the PWL, and a 20 s cutoff was set to avoid tissue damage.

A rotarod test was used to determine whether fluorocitrate would cause the motor function impairment as neurotoxicity of fluorocitrate. Rats were placed on an accelerating rod (IITC Life Science) beginning at $4 \mathrm{rpm}$ for three sessions per day for 2 consecutive days before administration. Over $300 \mathrm{~s}$, the rotating rod underwent a linear acceleration from 4 to $40 \mathrm{rpm}$, and animals were scored for their latency (in seconds) to fall for each trial. Rats were given a $15 \mathrm{~min}$ rest between trials to avoid fatigue. Fluorocitrate $(0.8 \mu \mathrm{g}=1 \mathrm{nmol}, 10 \mu \mathrm{l})$ or vehicle was intrathecally injected once daily for $6 \mathrm{~d}$, and the animals were tested on the rotarod at $24 \mathrm{~h}$ after the last intrathecal injection. Rotarod data are expressed as the average latency to fall of three sessions for each animal.

Terminal deoxynucleotidyl transferase-mediated fluorescein FragEL DNA fragmentation detection. The transverse sections of L4-L6 segments from normal rats and bone cancer rats with intrathecal administration of fluorocitrate $(0.8 \mu \mathrm{g}=1 \mathrm{nmol}, 10 \mu$ l, once daily for $6 \mathrm{~d})$ or sterile PBS $(n=2 \sim 4)$ were stained with a fluorescein FragEL DNA fragmentation detection kit (Calbiochem QIA39, EMD Millipore). The sections were incubated with proteinase $\mathrm{K}$ for $10 \mathrm{~min}$ at room temperature (RT), with terminal deoxynucleotidyl transferase (TdT) equilibrium buffer for 15 min at RT, and then with a TdT labeling reaction mixture at $37^{\circ} \mathrm{C}$ for $1-1.5 \mathrm{~h}$ in a humidified chamber. The positive control was made using HL-60 cells. The specific protocol was the same as before except that the specimen was first incubated with $1 \mu \mathrm{g} / \mu \mathrm{l}$ DNase I in $1 \times$ TBS $(20 \mathrm{~mm}$ Tris, $\mathrm{pH} 7.6 ; 140 \mathrm{~mm} \mathrm{NaCl}$ ) containing $1 \mathrm{~mm} \mathrm{MgSO} 4$ at RT for $20 \mathrm{~min}$ and then directly with TdT equilibrium buffer. The same specimens were examined with different filters. The total cell population was visualized using a filter for DAPI $(330-380 \mathrm{~nm})$. The fluorescein-labeled nuclei were analyzed using a standard fluorescein filter at $465-495 \mathrm{~nm}$. 


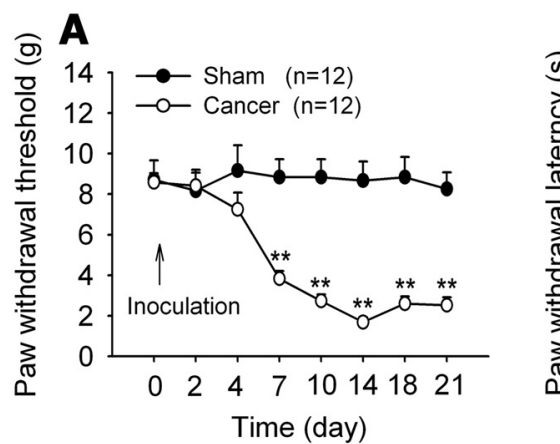

\section{B}

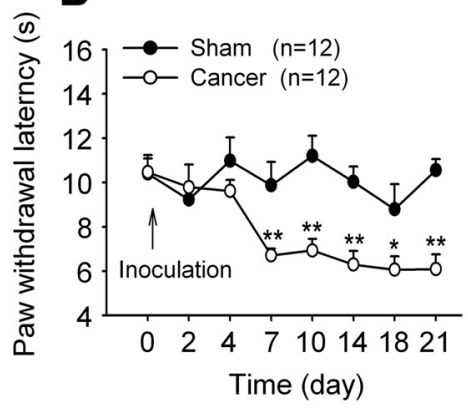

D Contr. Ipsi.

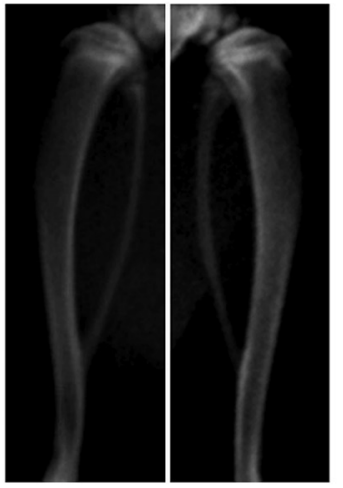

Sham 14d

\begin{abstract}
Contr.
\end{abstract}

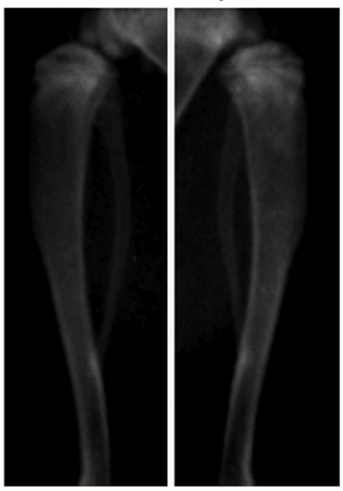

PTD 7

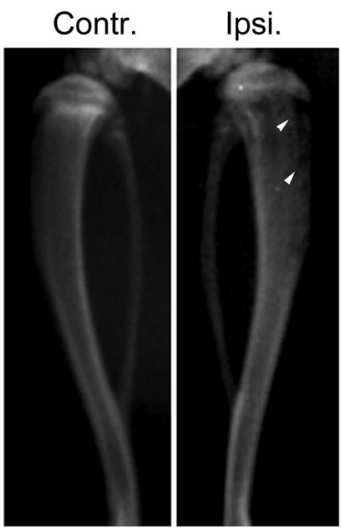

PTD 14
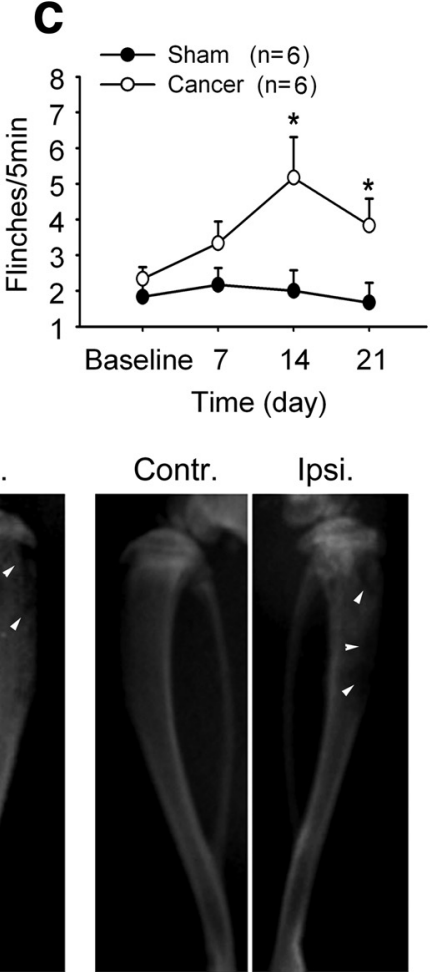

PTD 21

Figure 1. Bone cancer induces behavioral hypersensitivity and bone destruction. $A, B$, Intratibia inoculation with Walker 256 mammary gland carcinoma cells $\left(4 \times 10^{5}\right)$ induces significant mechanical allodynia $(\boldsymbol{A})$ and thermal hyperalgesia $(\boldsymbol{B})$ in the ipsilateral hindpaw. $\boldsymbol{C}$, Intratibia inoculation with Walker 256 mammary gland carcinoma cells induces spontaneous flinches in the hindpaw ipsilateral to the affected limb. The number of times the hindpaw was counted per 5 min during a $10 \mathrm{~min}$ observation period, and the average number of flinches per $5 \mathrm{~min}$ were calculated. ${ }^{*} p<0.05$; ${ }^{* *} p<0.01$ versus sham rats. D, Radiographs represent robust radiolucent lesions of the tibia ipsilateral to the tumor-bearing limb on PTDs 14 and 21 . Contr., Contralateral; Ipsi., ipsilateral.

Western blotting. Rats were killed with overdoses of urethane, and the L4-L6 spinal cord segment was rapidly removed. The dorsal horn tissues were homogenized in lysis buffer containing a mixture of protease inhibitors and phenylmethylsulfonyl fluoride (Roche Diagnostics). Equal amount of protein $(\sim 20 \mu \mathrm{g})$ was loaded and separated on $10 \%$ SDSPAGE gels (Bio-Rad) and transferred to PVDF membranes (Millipore). The membranes were incubated overnight at $4^{\circ} \mathrm{C}$ with primary antibodies, followed by HRP-conjugated secondary antibodies (1:1000; Pierce) for $2 \mathrm{~h}$ at $4^{\circ} \mathrm{C}$. GAPDH antibody was probed as a loading control. Signals were visualized using enhanced chemiluminescence (Pierce), and captured by ChemiDoc XRS system (Bio-Rad). We used the following primary antibodies: mouse anti-GFAP (1:20000; Sigma-Aldrich); rabbit anti-IBA-1 (1:1000; Wako Pure Chemical Industries); rabbit anti-P2X7R (1:2000; Alomone Labs); rabbit anti-phospho-p38 (p-p38) MAPK (ser180/182; 1:500; Cell Signaling Technology); rabbit anti-p38 MAPK (1:500; Cell Signaling Technology); and goat anti-IL-18 (1:1000; R\&D Systems).

All Western blot analysis was performed three to four times, and consistent results were obtained. A Bio-Rad image analysis system was then used to measure the integrated optic density of the specific bands.

Measurement of ATP content. Spinal CSF was collected from an intrathecal catheter. To prevent degradation of ATP, ecto-ATPase (1 $\mathrm{mmol} / 20 \mu \mathrm{l}$; Sigma-Aldrich) was intrathecally injected before CSF collection. ATP concentration was measured using an ENLITEN ATP Assay System with a bioluminescence detection kit (Promega). Briefly, samples $(90 \mu \mathrm{l})$ were neutralized to $\mathrm{pH} 7.4$ with $10 \mu \mathrm{l}$ of $4 \mathrm{~m}$ Tris. The luciferase reagent was added $1 \mathrm{~s}$ before a $5 \mathrm{~s}$ measurement in a luminometer, as described by the supplier (Promega). Light photons were measured by the luminometer and compared with the standard curve to calculate ATP concentration.

Immunohistochemistry. Rats were deeply anesthetized with overdoses of urethane and were transcardially perfused with normal saline followed by $4 \%$ paraformaldehyde in $0.1 \mathrm{~m} \mathrm{~PB}$. The L4-L6 segments of the spinal cord were removed and postfixed for $2-4 \mathrm{~h}$ at $4^{\circ} \mathrm{C}$, and then dehydrated in gradient sucrose at $4^{\circ} \mathrm{C}$. Transverse spinal cord sections $(30 \mu \mathrm{m})$ were cut on a cryostat (model 1900, Leica). The sections were blocked with $10 \%$ donkey serum with $0.3 \%$ Triton X-100 for $2 \mathrm{~h}$ at RT and incubated for $24-36 \mathrm{~h}$ at $4^{\circ} \mathrm{C}$ with rabbit anti-IBA-1 (1:500) or mouse anti-GFAP (1:2000) antibodies. The sections were then incubated for $2 \mathrm{~h}$ at RT with rhodamine-conjugated secondary antibodies (1:200; Jackson ImmunoResearch). For double immunofluorescence, the sections were incubated with a mixture of rabbit anti-P2X7R (1:400) and mouse anti-NeuN (1:2000; Millipore Bioscience Research Reagents)/OX-42 (1:200; CD11b antibody, Serotec)/GFAP/goat anti-IL-18 (1:500), or rabbit anti-p-p38 (1:500), and mouse anti-NeuN/GFAP/OX42/goat anti-IL-18, or goat anti-IL-18, and mouse anti-NeuN/GFAP/rabbit anti-IBA-1 (1:500) primary antibodies. The sections were then incubated with a mixture of rhodamine and FITC-conjugated secondary antibodies (1:200; Jackson ImmunoResearch) for $2 \mathrm{~h}$ at RT. The specificities of the immunostaining and primary antibodies were tested in previous studies (Chen et al., 2012) or were verified by the corresponding blocking peptide preabsorption experiments or in gene knock-out mice (e.g., P2X7R knock-out mice). The stained sections were observed and captured with a confocal laserscanning microscope (model FV1000, Olympus). Because the morphology of astrocytes and microglia is complex, and the immunoreactive staining includes both cell bodies and their processes, cell counts may not be sufficient to quantify glial activation. Therefore, the intensity of immunofluorescence of IBA-1-IR (or CD11b-IR) and GFAP-IR within the spinal dorsal horn (laminae I-VI) were measured with the Leica Qwin 500 image analysis system at six randomly selected sections for each animal.

In vivo extracellular recording. Rats were anesthetized with urethane $(1.5 \mathrm{~g} / \mathrm{kg}$, i.p.), and the trachea was cannulated to allow artificial respiration. A laminectomy was performed at vertebrae T13-L1 to expose the lumbar enlargement of the spinal cord. An intrathecal catheter (PE-10) 


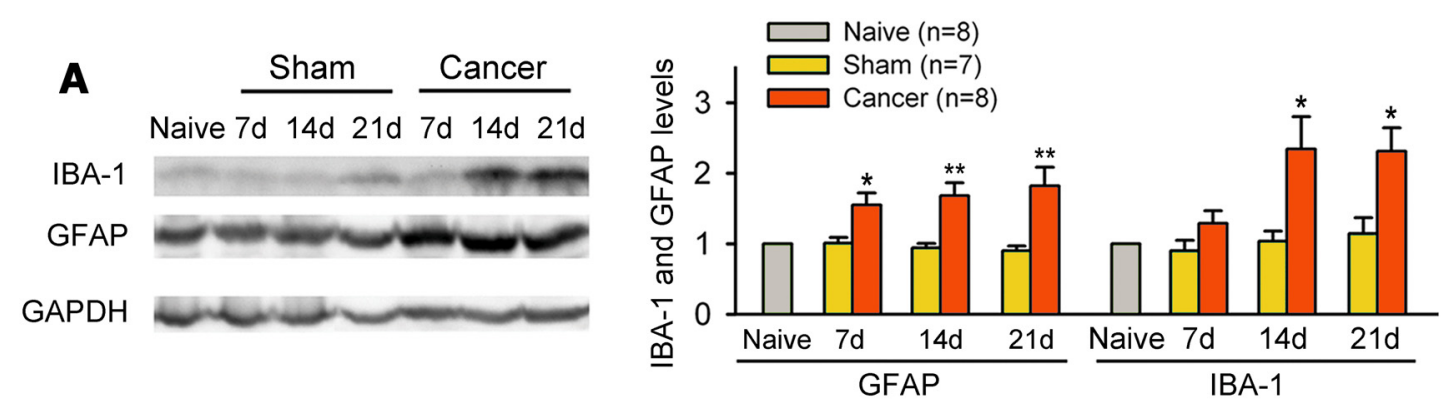

B
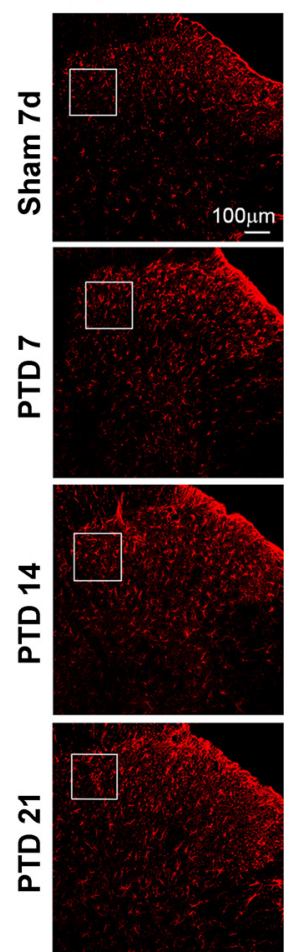

GFAP
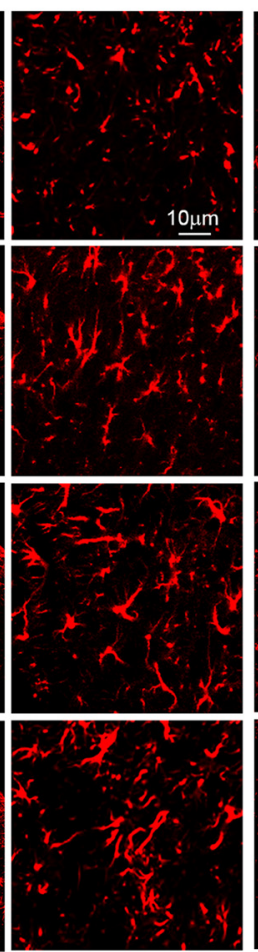

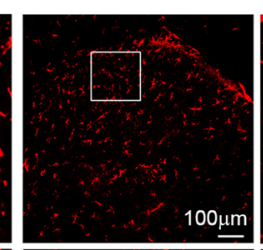

IBA-1
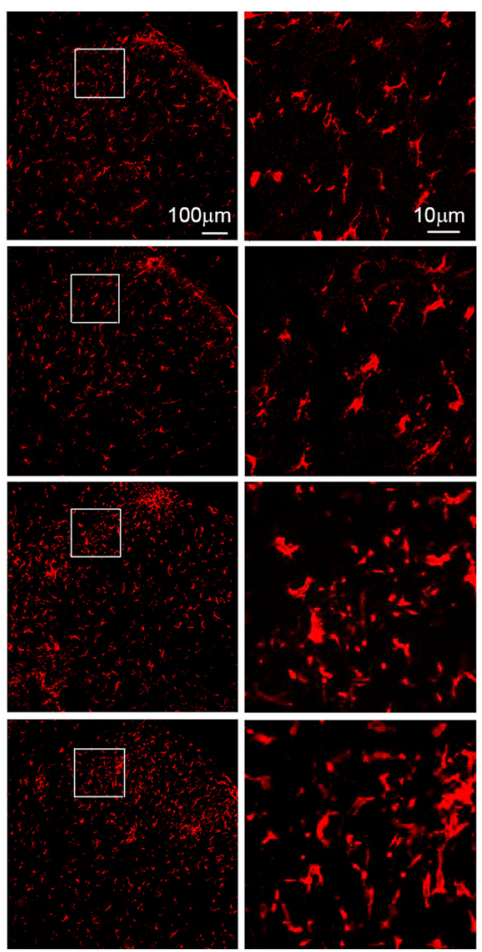
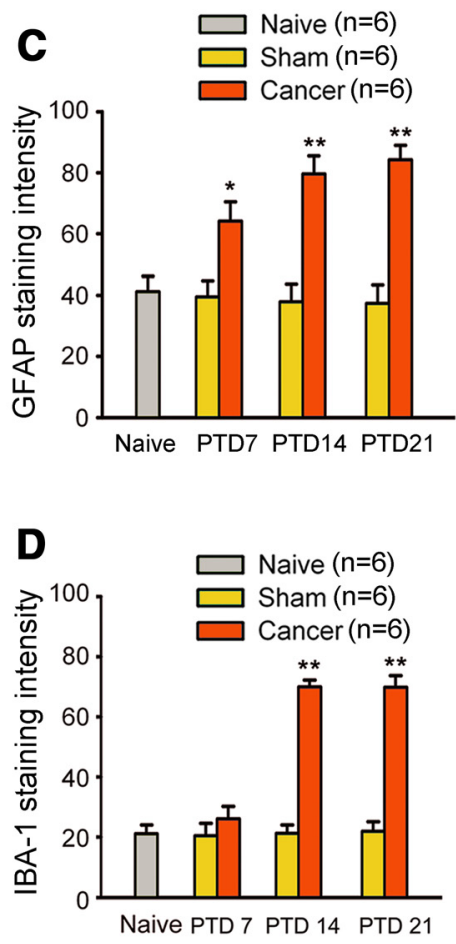

Figure 2. Time course of astrocytic and microglial activation on the lumbar spinal cord following bone cancer. $\boldsymbol{A}$, Western blot analysis reveals an early upregulation of GFAP from PTD 7 and a delayed upregulation of IBA-1 from PTD 14 in the ipsilateral L3-L5 spinal dorsal horn. $\boldsymbol{B}-\boldsymbol{D}$, Immunohistochemisty data show astrogliosis, as indicated by intense GFAP immunoreactivity and hypertrophied astrocytes with thick processes, and microgliosis, as indicated by intense IBA-1 immunoreactivity and large cell bodies and short or thick processes of microglia in the ipsilateral spinal dorsal horn. Astrogliosis and microgliosis occurred from early phase (PTD 7) and advanced phase (PTD 14), respectively. ${ }^{*} p<0.05 ;{ }^{* *} p<0.01$ versus sham rats.

was made for drug injection. The vertebral column was rigidly fixed in the frame with clamps. The exposed spinal cord was covered by warm $\left(37^{\circ} \mathrm{C}\right)$ saline solution. After surgery, the animal was immobilized and artificially ventilated (Capstar-100, IITC Life Science). End-tidal $\mathrm{CO}_{2}$ was maintained at $3.5-4.5 \%$, and the rectal temperature was maintained at $37-38^{\circ} \mathrm{C}$ by a feedback-controlled heating blanket. The electrocardiogram was monitored, and the heart rate was maintained at 250-300 beats/min.

As we reported previously (Lü et al., 2010), single-unit extracellular recordings were made at L4-L5 segments, 300-700 $\mu \mathrm{m}$ from the surface of the spinal cord with a glass micropipette filled with $0.5 \mathrm{~m}$ sodium acetate (impedance, $8-10 \mathrm{M} \Omega$ at $1000 \mathrm{~Hz}$ ). The micropipette was inserted perpendicularly to the spine into the dorsal horn from a point about midway between the midline and medial edge of the dorsal root entry zone. Each neuron was functionally identified as a wide dynamic range (WDR) neuron on the basis of their responses to innocuous or noxious mechanical stimulation to the receptive fields (RFs) in the plantar region of the hindpaw. WDR neurons responding to innocuous stimulation and to a greater degree, noxious stimulation of the RF were analyzed in the present study. The recorded signals were amplified with a microelectrode amplifier (1800 A-M System) and were fed to computer via a CED 1401 interface for off-line analysis using the
Spike 2 software (Cambridge Electronic Design). For low-intensity mechanical stimulation, graded stimuli with von Frey filaments (4, $8,15,26$, and $60 \mathrm{~g}$ ) were applied for $15 \mathrm{~s}$ at $30 \mathrm{~s}$ intervals. Highintensity (pinch) stimulation with pinch produced by a clip (150 g) was also applied for $15 \mathrm{~s}$. In pharmacological studies, only one cell was studied in each animal.

Preparation of spinal cord slices and whole-cell patch-clamp recordings. Spinal slices were obtained from young rats. As we reported previously (Zhang et al., 2012), the L4-L5 lumbar spinal cord segment was rapidly removed under deep anesthesia with isoflurane and kept in preoxygenated ice-cold sucrose artificial CSF (ACSF). Transverse slices $(500 \mu \mathrm{m})$ were cut on a vibrating microslicer and incubated in preoxygenated recording ACSF for at least $1 \mathrm{~h}$ at $32 \pm 1^{\circ} \mathrm{C}$ before the experiment. Slices were then transferred into a recording chamber and continuously perfused with recording solution at a rate of $5 \mathrm{ml} / \mathrm{min}$ at $\mathrm{RT}$. The recording ACSF contains the following (in mM): $\mathrm{NaCl} 125, \mathrm{KCl} 2.5, \mathrm{CaCl}_{2} 2, \mathrm{MgCl}_{2}$ $1, \mathrm{NaH}_{2} \mathrm{PO}_{4} 1.25, \mathrm{NaHCO}_{3} 26$, D-glucose 25, ascorbate 1.3, and sodium pyruvate 3.0.

The whole-cell patch-clamp recordings were made from lamina IIo neurons in voltage-clamp mode. Patch pipettes (5-10 M $\Omega$ ) were made from borosilicate glass on a horizontal micropipette puller (P-97, Sutter Instruments) and were filled with a solution of the following composi- 
A

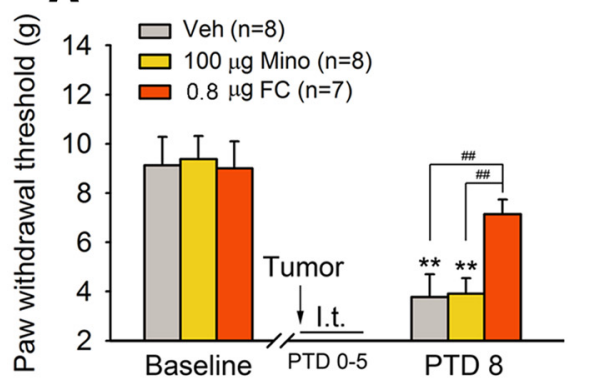

D

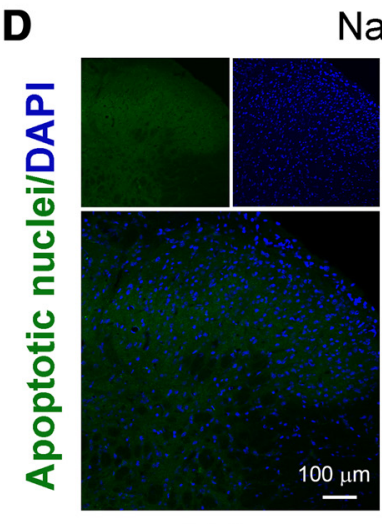

Veh

Naive
B

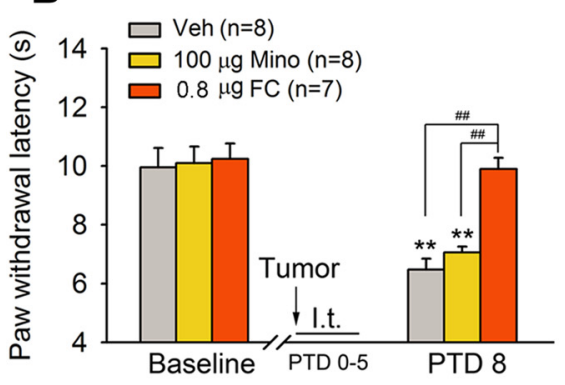

PTD 14

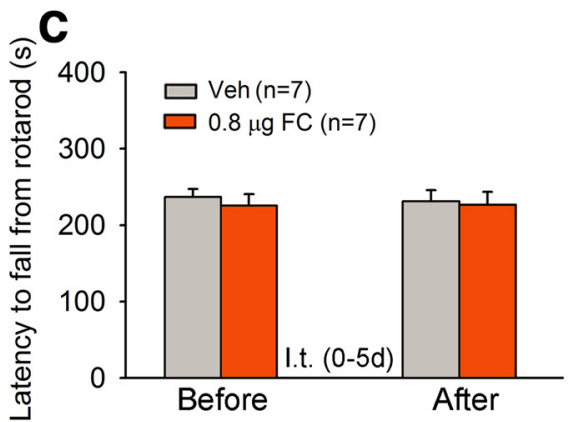

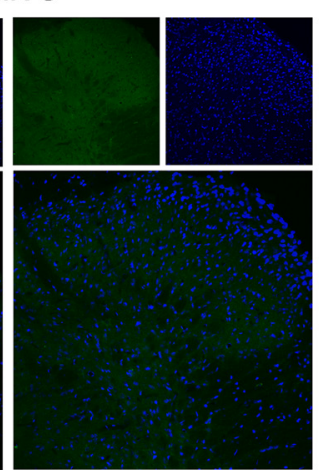

FC

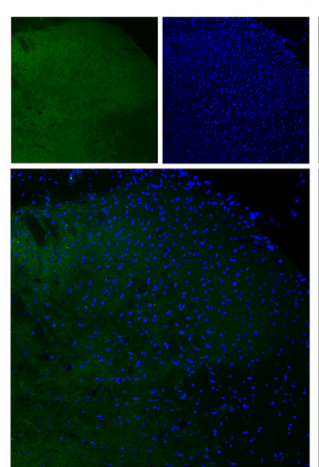

Veh

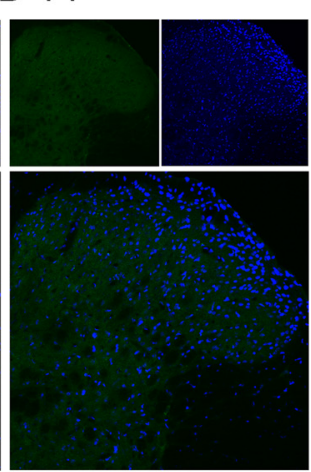

FC
Positive control

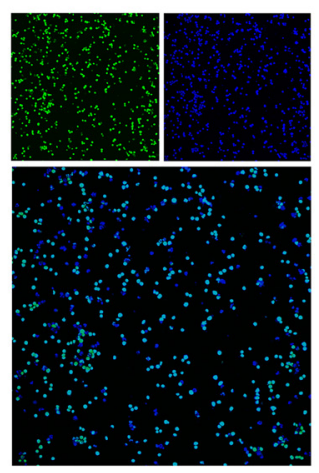

HL-60 cells

\section{E}

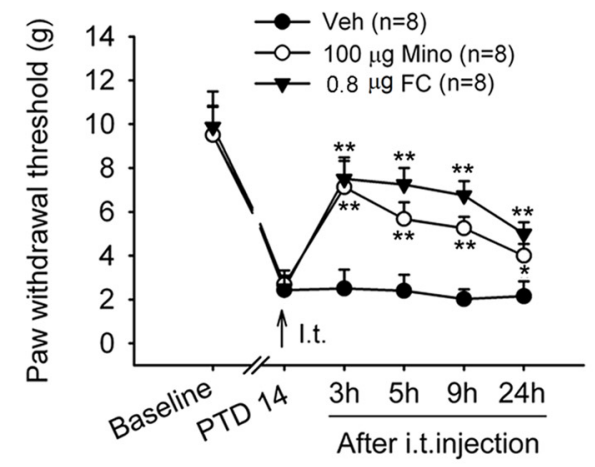

$\mathbf{F}$

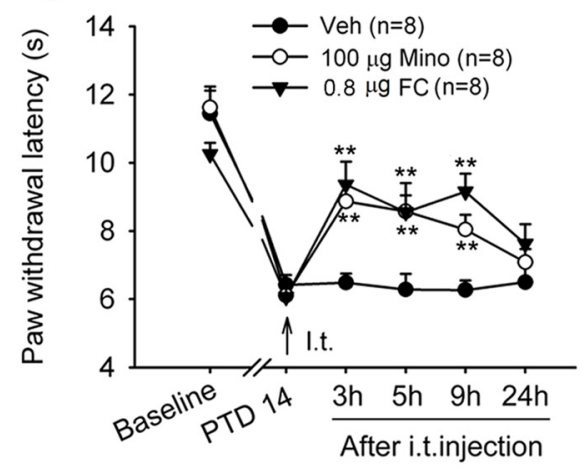

Figure 3. Delayed activation of microglia is involved in the maintenance, but not the induction, of bone cancer pain. $\boldsymbol{A}, \boldsymbol{B}$, Development of mechanical allodynia $(\boldsymbol{A})$ and thermal hyperalgesia ( $\boldsymbol{B})$ is blocked by repeated intrathecal injections of astrocyte metabolic inhibitor fluorocitrate (FC; $0.8 \mu \mathrm{g}=1 \mathrm{nmol}$ ) but not by microglia inhibitor minocycline (Mino; $100 \mu \mathrm{g}$ ) during the early phase of bone cancer pain. FC or Mino is given once daily for $6 \mathrm{~d}$ with the first injection occurring 30 min before intratibia inoculation. ${ }^{* *} p<0.01$ versus baseline. \#\#p $<0.01$ versus vehicle (Veh)- and Mino-treated groups. $\boldsymbol{C}$, Repeated intrathecal injections of FC ( $0.8 \mu \mathrm{g}=1 \mathrm{nmol}$, once daily for $6 \mathrm{~d})$ do not influence motor coordination in normal rats in a rotarod test. $\boldsymbol{D}$, Few fluorescein-labeled apoptotic nuclei were detected in the lumbar spinal dorsal horns from normal or bone cancer rats with repeated intrathecal injections of FC ( $0.8 \mu \mathrm{g}=1 \mathrm{nmol}$, once daily for $6 \mathrm{~d})$. $\mathrm{HL}-60$ cells treated by $0.5 \mu \mathrm{g} / \mathrm{ml}$ actinomycin D for $19 \mathrm{~h}$ to induce apoptosis were used as a positive control. $\boldsymbol{E}, \boldsymbol{F}$, Intrathecal injection of either FC or Mino on PTD 14 significantly reduces bone cancer-induced mechanical allodynia $(\boldsymbol{E})$ and thermal hyperalgesia $(\boldsymbol{F}) .{ }^{*} p<0.05 ;{ }^{* *} p<0.01$ versus vehicle controls.

tion (in mM): potassium gluconate $120, \mathrm{KCl} 20, \mathrm{MgCl}_{2}$ 2, Na2ATP 2, NaGTP 0.5, HEPES 20, EGTA 0.5, with the pH adjusted to 7.2 and osmolarity adjusted to $300 \mathrm{mOsm} / \mathrm{L}$. Membrane currents were amplified with an Axopatch 700B amplifier (Molecular Devices). Signals were filtered at $2 \mathrm{kHz}$ and digitized at $5 \mathrm{kHz}$ with a digitizer (Digidata 1322, Molecular Devices). Miniature EPSCs (mEPSCs) were recorded at a holding potential of $-70 \mathrm{mV}$ in the presence of tetrodotoxin $(1 \mu \mathrm{M})$ and picrotoxin $(50 \mu \mathrm{M})$. Data were collected with pClamp version 10.1 software and analyzed with Mini Analysis (Synaptosoft).

Data analysis and statistics. Data are presented as the mean \pm SEM. The sample sizes for each experiment are described in Table 1. Student's $t$ test; paired $t$ test; and one-way, two-way, or two-way repeated-measures ANOVA followed by post hoc Student-Newman-Keuls test were used to identify significant differences. A $p$ value of $<0.05$ was considered to be statistically significant.

\section{Results}

Delayed activation of microglia contributes to the maintenance but not the initiation of bone cancer pain Consistent with our previous studies (Duan et al., 2012; Xu et al., 2013), following tumor inoculation, mechanical allodynia, thermal hyperalgesia, and spontaneous flinching behavior developed in $7 \mathrm{~d}$, peaked at day 14 , and persisted for at least $21 \mathrm{~d}$ in the ipsilateral hindpaw of the affected limb. Two-way repeatedmeasures ANOVA showed significant main effects of tumor inoculation (PWTs: $F_{(1,22)}=63.305, p<0.001$; PWLs: $F_{(1,22)}=$ 48.26, $p<0.001$; spontaneous flinches: $F_{(1,10)}=18.846, p=$ 0.007; Fig. $1 A-C)$. The radiographs showed signs of radiolucent lesions in the tibia close to the injection sites of tumor cells, 
especially at the proximal epiphysis, on post-tumor days (PTDs) 14 and 21 (Fig. 1D).

Previous studies in male rats and mice showed that early microglial activation appears to be important for the initiation and development of neuropathic and inflammatory pain, whereas delayed astrocytic activation may play a role in maintaining the pain (Raghavendra et al., 2003; Ledeboer et al., 2005; Shan et al., 2007; Sun et al., 2008). In the present study, we further examined the time course of microglial and astrocytic activation in the spinal cord of female rats with bone cancer pain. Western blot analysis showed an early and sustained elevation of GFAP (astrocytic marker) in the spinal dorsal horn during the early ( $7 \mathrm{~d})$, advanced $(14 \mathrm{~d})$, and late $(21 \mathrm{~d})$ phases of bone cancer pain, which were associated with the development of behavioral hypersensitivity. In sharp contrast, the significant upregulation of microglial marker IBA- 1 was not observed at PTD 7 but only at PTDs 14 and 21 (Fig. 2A). Distinct activation of astrocytes and microglia in bone cancer pain was further confirmed by immunohistochemistry (Fig. 2B-D).

Next, we tested the effects of fluorocitrate (an astrocyte metabolic inhibitor) and an inhibitor of microglial activation minocycline on the development of bone cancer-induced allodynia and hyperalgesia. Intrathecal injection of fluorocitrate $(0.8 \mu \mathrm{g}=$ $1 \mathrm{nmol}, 10 \mu \mathrm{l}$ ) once daily for $6 \mathrm{~d}$ with the first injection $1 \mathrm{~h}$ before tumor inoculation significantly inhibited the development of bone cancer-induced mechanical allodynia and thermal hyperalgesia. Three days after cessation of the intrathecal treatment, allodynia and hyperalgesia were still reliably suppressed (Fig. $3 A, B)$. On the contrary, early repeated intrathecal injections of minocycline $(100 \mu \mathrm{g})$ did not prevent the development of bone cancer-induced allodynia and hyperalgesia (Fig. $3 A, B$ ). To rule out the neurotoxic effect of multiple fluorocitrate injections, a rotarod test was performed to explore the potential motor impairment, as a form of neurotoxicity (Esmaeili et al., 2012). As shown in Figure $3 C$, intrathecal injections of fluorocitrate $(0.8$ $\mu \mathrm{g}=1 \mathrm{nmol}$ ) once daily for $6 \mathrm{~d}$ did not affect the mean latency time to fall from the rod in naive rats. To examine whether multiple fluorocitrate injection would cause cell damage in the spinal dorsal horn, we examined apoptosis using a TdTmediated fluorescein FragEL DNA fragmentation detection kit. Few fluorescein-labeled apoptotic cell nuclei were seen on the bilateral spinal dorsal horn in the normal and bone cancer rats, and multiple fluorocitrate injections did not increase apoptotic cell nuclei (Fig. 3D). Together, these results suggest that spinal injections of fluorocitrate, at the dose we used, did not produce obvious neurotoxicity.

To examine whether fluorocitrate and minocycline would reverse advanced cancer pain, intrathecal injection of fluorocitrate or minocycline was given on PTD 14. As shown in Figure 3, E and F, bone cancer-induced mechanical allodynia and thermal hyperalgesia were significantly attenuated for $>9 \mathrm{~h}$ by a single application of either fluorocitrate or minocycline (two-way repeated-measures ANOVA: treatments: PWTs, $F_{(2,56)}=19.916, p<0.001$; PWLs, $\left.F_{(2,56)}=8.368, p=0.003\right)$. These results suggest that delayed activation of microglia contributes to the maintenance of bone cancer pain in female rats.

\section{P2X7R mediates bone cancer-induced microglial activation} and behavioral hyperalgesia

The previous studies from our and other laboratories showed that in the spinal cord P2X7R protein and mRNA were exclusively expressed in microglia in normal conditions, and under peripheral nerve injury and morphine tolerance conditions
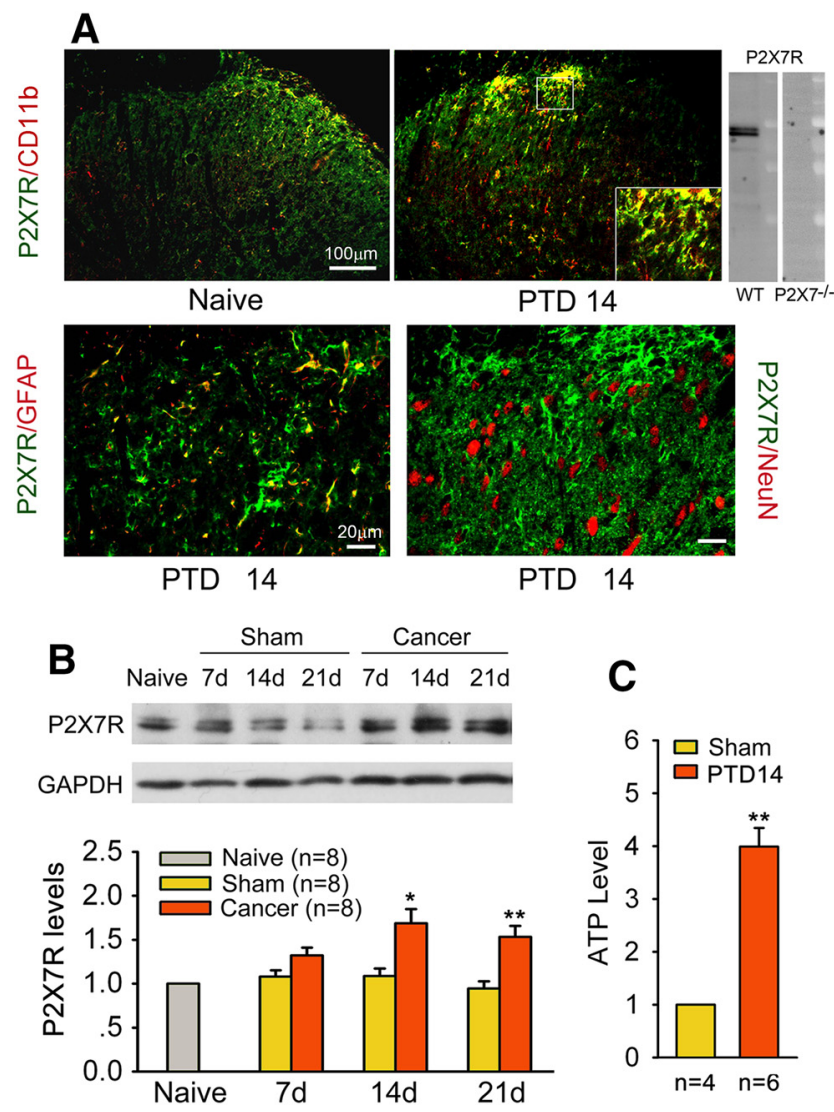

Figure 4. Bone cancer induces the upregulation of $P 2 X 7 R$ in the spinal dorsal horn and increases ATP release in spinal CSF. $A$, Double immunofluorescence reveals that P2X7R-IR is predominantly colocalized with CD11b-IR (microglial marker), but not with NeuN-IR (neuronal marker), on the ipsilateral spinal dorsal horn. Inset, The antibody to P2X7 detected a band corresponding to P2X7R in wild-type mice but not in P2X7R knock-out mice. $B$, Western blot analysis reveals significant upregulation of P2X7R levels on PTDs 14 and 21. C, ATP concentration in spinal CSF was significantly increased on PTD 14. ${ }^{*} p<0.05,{ }^{* *} p<0.01$ versus sham rats.

(Zhou et al., 2010; Kobayashi et al., 2011; He et al., 2012). To identify the cell types expressing the P2X7R following bone cancer pain, we performed double immunostaining of P2X7R with cell-specific markers, including NeuN for neurons, GFAP for astrocytes, and CD11b (labeled by the antibody OX-42) for microglia on sections of the L4 spinal cord. P2X7R-IR cells coexpressing $\mathrm{CD} 11 \mathrm{~b}$ were detected sparsely in the superficial laminae of naive rats (Fig. 4A). Increased P2X7R-IR appeared on PTD 14. The specificity of P2X7R antibody was verified in $\mathrm{p} 2 \mathrm{x} 7$ receptor gene knock-out mice first (Fig. 4A). P2X7R was predominantly colocalized with $\mathrm{CD} 11 \mathrm{~b}$, with minor colocalization with GFAP and no colocalization with NeuN (Fig. 4A). The P2X7R and $\mathrm{CD} 11 \mathrm{~b}$ or GFAP double-labeled area in the dorsal horn was measured in six spinal sections from three PTD 14 rats, and the P2X7R/CD11b double-labeled area accounted for $80 \%$ of the P2X7R single-labeled area, which was 20\% in P2X7R/GFAP double staining. Western blot analysis showed significant upregulation of P2X7R on PTDs 14 and 21 (one-way ANOVA: $F_{(6,46)}=$ $3.635, p=0.005$; Fig. $4 B$ ), which is consistent with the time course of IBA-1 upregulation.

To confirm whether bone cancer pain results in increased release of ATP, the ligand for P2X7R, we measured ATP concentration in CSF on PTD 14. Compared with the sham rats, the CSF ATP level was significantly increased in PTD 14 rats (Student's $t$ test: $t_{(0.01,18=6.834)}, p<0.001$; Fig. $\left.4 C\right)$. 

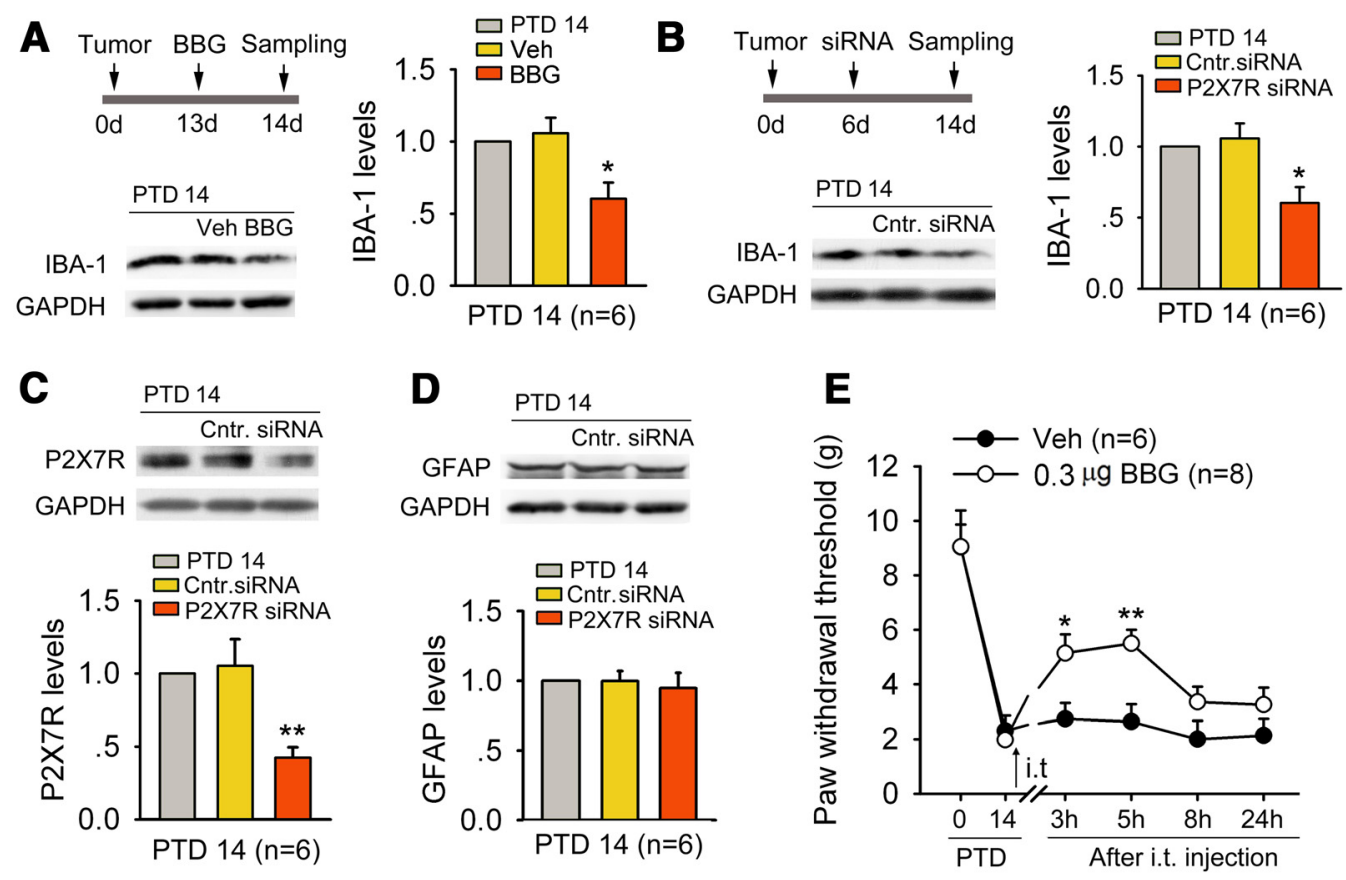

$\mathbf{F}$

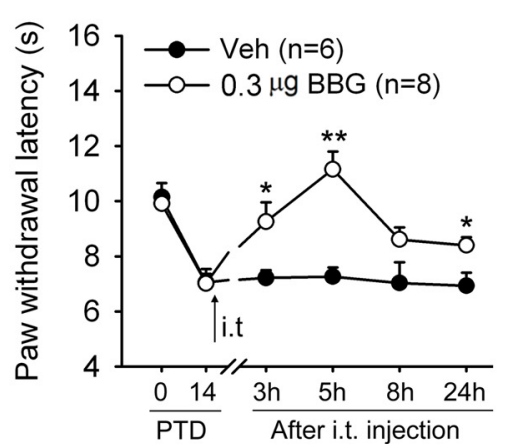

G

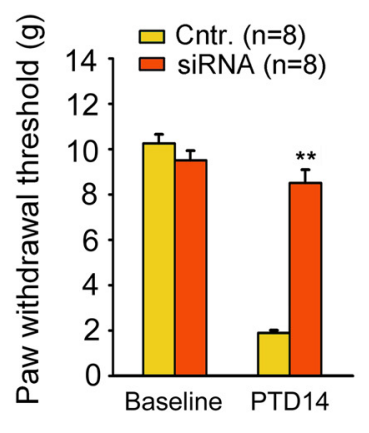

H

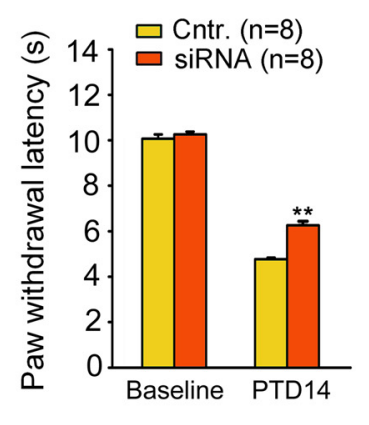

Figure 5. P2X7R is involved in microglial activation, and bone cancer-induced allodynia and hyperalgesia in advanced phase. $A$, Blockade of P2X7R by BBG (a selective P2X7R antagonist; $0.3 \mu \mathrm{g}$, i.t.) significantly suppressed bone cancer-induced IBA-1 upregulation on PTD $14 .{ }^{*} p<0.01$ versus vehicle control (Veh). $B, C$, Knockdown of P2X7R by siRNA ( $5 \mu \mathrm{g}$ ) targeted against P2X7R blocks bone cancer-induced IBA-1 (B) and P2X7R (C) upregulation on PTD 14. ${ }^{*} p<0.05$, ${ }^{* *} p<0.01$ versus control siRNA (Cntr.). D, Increased GFAP level on PTD 14 is not suppressed by P2X7R siRNA. $\boldsymbol{E}$, $\boldsymbol{F}$, Intrathecal injection of BBG on PTD 14 significantly reduces bone cancer-induced mechanical allodynia $(\boldsymbol{E})$ and thermal hyperalgesia $(\boldsymbol{F}) .{ }^{*} p<0.05 ;{ }^{* *} p<0.01$ versus vehicle controls. $\boldsymbol{G}, \boldsymbol{H}$, Knockdown P2X7R by siRNA blocks bone cancer-induced allodynia $(\boldsymbol{G})$ and hyperalgesia $(\boldsymbol{H}) .{ }^{* *} p<0.01$ versus control siRNA.

We used different pharmacological approaches to test an essential role of spinal P2X7R in cancer-induced microglial activation. Intrathecal administration of a selective P2X7R antagonist, BBG $(0.3 \mu \mathrm{g}=400 \mathrm{pmol})$, significantly inhibited bone cancerinduced IBA-1 upregulation on PTD 14 (one-way ANOVA: $F_{(2,15)}=4.082, p=0.038$; Fig. $5 A$ ). Also, the IBA-1 upregulation on PTD 14 was significantly inhibited by siRNA $(5 \mu \mathrm{g})$ targeted against rat P2X7R (one-way ANOVA: $F_{(2,15)}=4.618, p=0.027$; Fig. $5 B$ ). The knockdown efficiency was determined by reduced P2X7R expression after the siRNA treatment (Fig. 5C). However, bone cancer pain-induced GFAP upregulation was not suppressed by P2X7R-siRNA in the spinal dorsal horn (Fig. 5D).

To address whether P2X7R is involved in bone cancerinduced allodynia and hyperalgesia, we observed the behavioral effects of BBG and P2X7R siRNA in the advanced phase. As shown in Figure 5, $E$ and $F$, intrathecal injection of BBG $(0.3 \mu \mathrm{g}=$ $400 \mathrm{pmol}$ ) significantly suppressed bone cancer-induced mechanical allodynia and thermal hyperalgesia on PTD 14 (two-way repeated-measures ANOVA for treatments: PWTs, $F_{(1,12)}=$ $18.419, p=0.008$; PWLs, $\left.F_{(1,12)}=9.904, p=0.025\right)$. Consis- tently, intrathecal injection of P2X7R-siRNA ( $5 \mu \mathrm{g})$ also significantly reduced bone cancer-induced allodynia and hyperalgesia (Fig. 5G,H). Neither BBG nor P2X7R siRNA had effects on PWT and PWL in naive rats.

\section{P2X7R mediates bone cancer-induced IL-18 upregulation in spinal microglia via $\mathrm{p} 38 \mathrm{MAPK}$}

Activation of $\mathrm{p} 38$ MAPK in spinal microglia drives neuropathic pain by producing the proinflammatory cytokine IL-18 (Miyoshi et al., 2008). Thus, we reasoned that P2X7R activation could cause IL-18 upregulation via p38 activation in spinal microglia. Bone cancer induced significant upregulation of p-p38 at PTDs 14 and 21 (one-way ANOVA: $F_{(6,46)}=5.339, p<0.001$; Fig. 6 A), when P2X7R upregulation was observed. Knockdown of P2X7R attenuated bone cancer-induced p-p38 (Fig. 6B).

Consistent with the temporal profiles of p-p38, P2X7R, and IBA-1 upregulation, significant elevation of IL-18 levels also occurred on PTDs 14 and 21 (one-way ANOVA: $F_{(6,46)}=3.566, p=$ 0.006; Fig. 6C). Knockdown of P2X7R markedly suppressed the cancer-induced IL-18 upregulation on PTD 14 (Fig. 6D). In- 

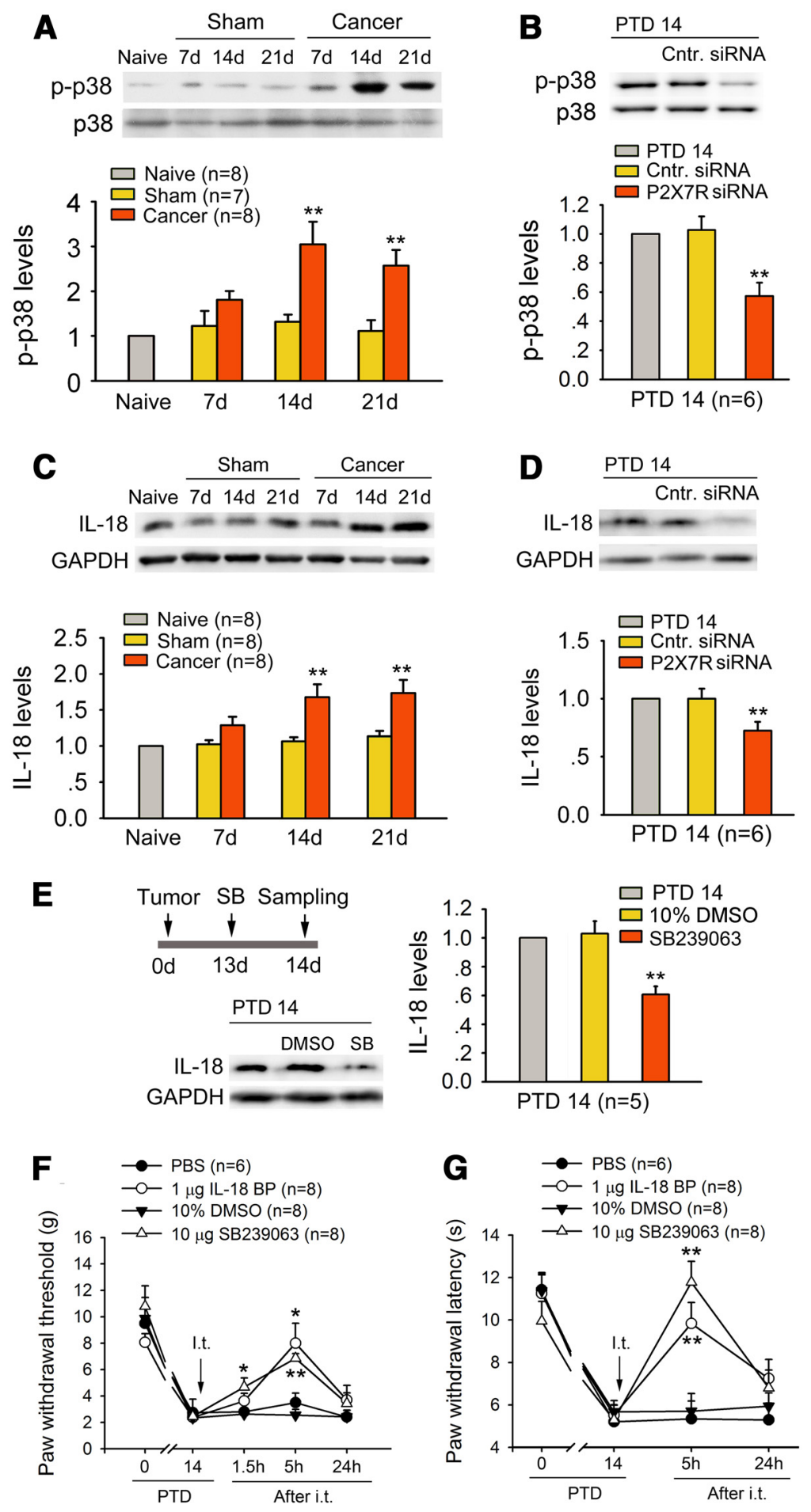

Figure 6. P2X7R mediates bone cancer-induced IL-18 upregulation via p38 MAPK in the spinal dorsal horn. $\boldsymbol{A}$, Western blot analysis reveals significant upregulation of p-p38 levels on PTDs 14 and 21. ${ }^{* *} p<0.01$ versus sham rats. $\boldsymbol{B}$, Knockdown P2X7R significantly reduces bone cancer-induced activation of $\mathrm{p} 38$ on PTD 14. ${ }^{* *} p<0.01$ versus control siRNA (Cntr.). C, Western blot analysis reveals significant upregulation of IL-18 levels on PTDs 14 and $21 .{ }^{* *} p<0.05$ versus sham rats. $\boldsymbol{D}$, Knockdown P2X7R significantly suppressed bone cancer-induced upregulation of IL-18 on PTD $14 .{ }^{* *} p<0.01$ versus control siRNA. $\boldsymbol{E}$, Selective p38 inhibitor SB239063 (SB; $10 \mu \mathrm{g}$, i.t.) markedly suppressed the bone cancer-induced increase in IL-18 levels on PTD 14. $\boldsymbol{F}$, $\mathbf{G}$, Intrathecal injection of SB239063 or IL-18BP (an endogenous inhibitor of IL-18 activity; $1 \mu \mathrm{g}$, i.t.) reversed bone cancer-induced mechanical allodynia $(\boldsymbol{F})$ and hyperalgesia (G) on PTD 14. ${ }^{*} p<0.05,{ }^{* *} p<0.01$ versus vehicle controls (PBS or DMSO).

hibition of p38 phosphorylation by intrathecal injection of a specific p38 inhibitor, SB239063, also attenuated the bone cancer-induced IL-18 increase (Fig. 6E). Importantly, intrathecal injection of SB239063 (10 $\mu$ g, i.t.) or IL-18BP ( $1 \mu \mathrm{g})$, a naturally occurring inhibitor of IL-18 activity with higher affinity for mature IL-18 (Alboni et al., 2010), effectively alleviated bone cancer-induced mechanical allodynia and thermal hyperalgesia on PTD 14 (Fig. $6 F, G)$.

Double immunostaining indicated that on PTD 14, IL-18-IR, exclusively expressed in p-p38-positive cells, and the majority of $\mathrm{p}$-p38-IR were found in OX42-IR microglia, rarely in NeuN-IR neurons, but not in GFAP-IR astrocytes in the spinal cord (Fig. 7A). IL-18-IR cells also express P2X7R and IBA-1 in the spinal dorsal horn. As shown in Figure $7 B$, there was increased expression of IL-18-IR in hypertrophic IBA-1-positive microglia, but not in astrocytes (GFAP-IR) and neurons (NeuN-IR) on PTD 14.

\section{P2X7R and IL-18 regulate neuronal activity in the spinal dorsal horn}

To determine whether bone cancer leads to increased neuronal activity in the spinal cord, WDR neurons were recorded in the dorsal horns of PTD 14 rats and sham control rats. Typical mechanically evoked responses of WDR neurons, elicited by innocuous mechanical stimulation (light touch with a brush) and noxious mechanical stimulation (pinch), are shown in Figure $8 A-C$. All the brushed, pinched, and graded mechanical stimuli-evoked responses were significantly larger in PTD 14 rats compared with the sham control rats (Fig. $8 D, E$ ).

Next, we examined the involvement of P2X7R and IL-18 in bone cancerinduced neuronal hyperactivity. As shown in Figure 8, $F$ and $G$, mechanical hyperactivity in spinal WDR neurons on PTD 14 was significantly depressed by P2X7R antagonist BBG $(0.3 \mu \mathrm{g}=400$ pmol, i.t.) and IL-18 inhibitor IL-18BP (1 $\mu$ g, i.t.). Notably, intrathecal injection of exogenous IL-18 (3 $\mu \mathrm{g})$ significantly increased mechanically evoked responses in WDR neurons from naive rats (Fig. $8 \mathrm{H}-$ $J)$. Consistently, intrathecal injection of exogenous IL-18 (0.03-3 $\mu \mathrm{g})$ dosedependently induced allodynia in naive rats, which was not prevented by fluorocitrate pretreatment $(0.8 \mu \mathrm{g}$; Fig. $8 K, L)$, suggesting that IL-18 signaling is a downstream event of glial activation.

Finally, we examined the effects of IL-18 on excitatory synaptic transmission in spinal cord slices in vitro by recording mEPSCs in spinal lamina IIo neurons. Superfusion of spinal cord slices with IL-18 (10 ng/ml) for $2 \mathrm{~min}$ rapidly and significantly increased the frequency of mEPSCs (paired $t$ test, $p<0.05$ ), indicating that IL-18 can modulate excitatory synaptic transmission via presynaptic glutamate release 
A
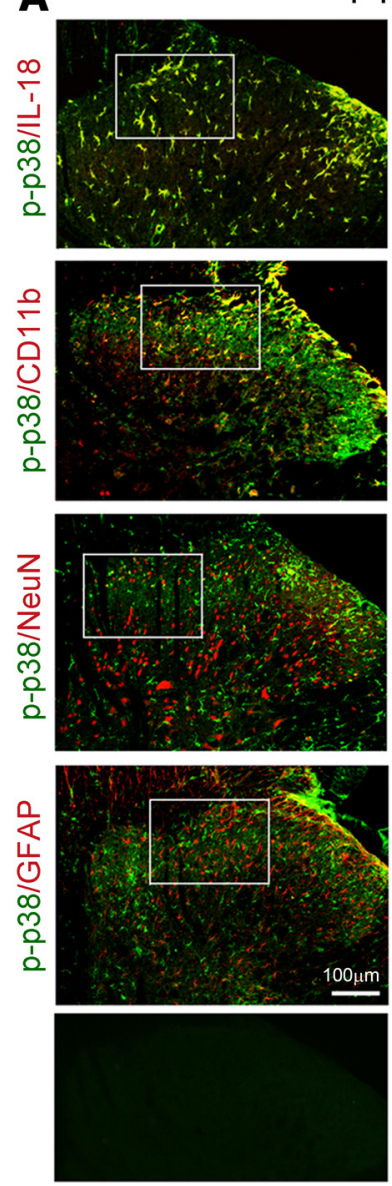

Omit primary

antibody
PTD 14
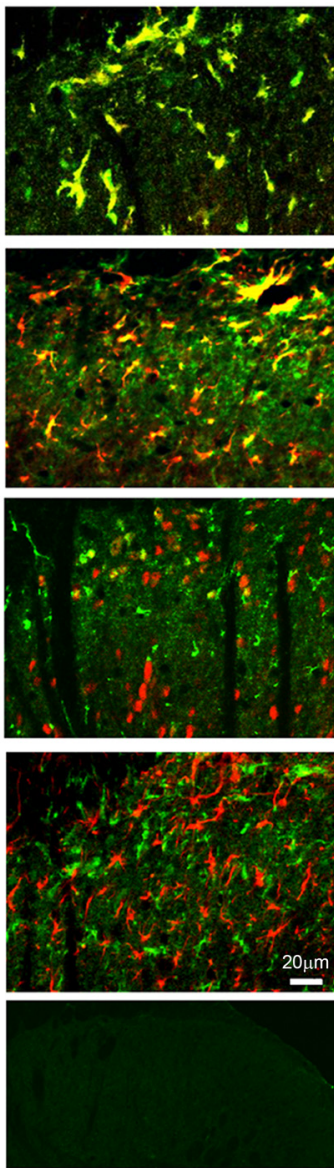

Anti-p-p38

+ blocking peptide
B
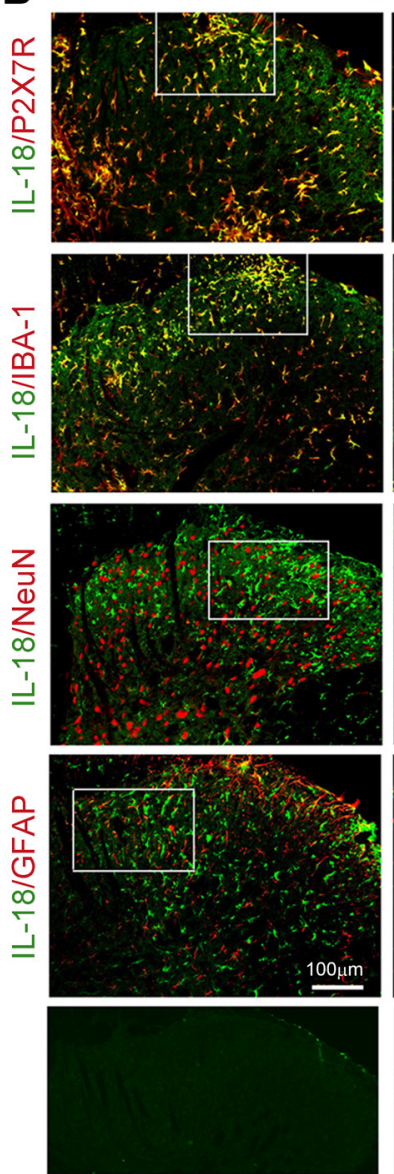

Anti-IL-18

+ blocking peptide
PTD 14
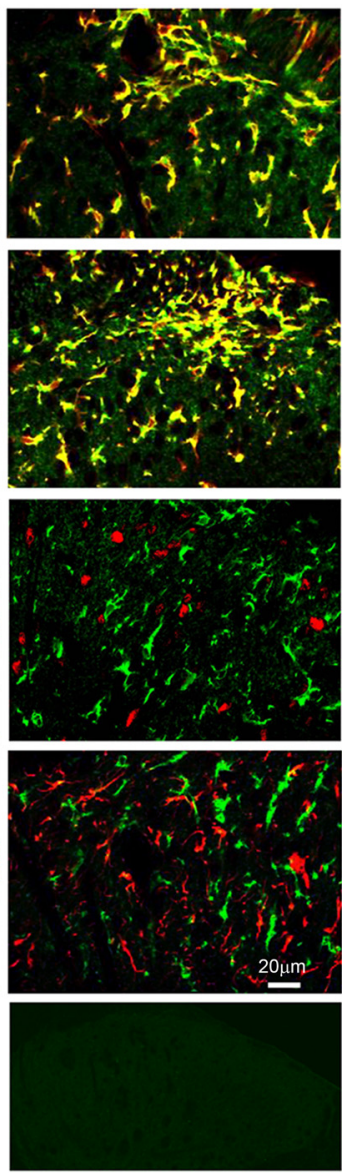

Anti-P2X7R

+ blocking peptide

Figure 7. Colocalization of P2X7R/p-p38 and IL-18 in spinal microglia. $A$, Double immunofluorescence of p-p38 with IL-18-IR, CD11b-IR, NeuN-, IR, and GFAP-IR on the ipsilateral spinal dorsal horn on PTD 14. Note the heavy colocalization of p-p38-IR with IL-18-IR and CD11b-IR. B, Double immunofluorescence shows colocalization of IL-18 with P2X7R and IBA-1 on the ipsilateral spinal dorsal horn on PTD 14.

(Fig. 9A-E). Of interest, the facilitation of mEPSCs by IL-18 was not suppressed by fluorocitrate $(10 \mu \mathrm{M}$; Fig. $9 F-I)$, suggesting a direct effect of IL-18 on synaptic transmission.

\section{Discussion}

Numerous studies, predominantly performed in male rats and mice, have demonstrated a critical role of microglia in the development of pain hypersensitivity in neuropathic and inflammatory pain (Raghavendra et al., 2003; Shan et al., 2007; Sun et al., 2008). However, our data from female rats provided several lines of evidence to support a critical role for spinal microglia in the maintenance of bone cancer pain symptoms. First, bone cancer elicited a delayed and persistent upregulation of a microglial marker (IBA-1) and microglial proliferation in the spinal dorsal horn. Second, spinal injection of a microglia inhibitor effectively reduced the established advanced-phase cancer pain, but did not prevent or delay the development of bone cancer-induced hyperalgesia and allodynia. Third, bone cancer induced P2X7R expression predominantly in spinal microglia, and the blockade of P2X7R suppressed microglia activation and relieved bone cancer pain. Fourth, bone cancer also induced a significant upregulation of IL-18 in spinal microglia, which depends on P2X7R and p-p38. Fifth, IL-18 is a key microglial mediator that triggers cancer pain by increasing mEPSC frequency in superficial dorsal horn neu- rons in spinal slices and by inducing the mechanical hyperactivity of WDR neurons in vivo.

\section{Spinal cord glial activation in bone cancer pain}

Activation of microglia and astrocytes has been regularly demonstrated in different models of neuropathic and inflammatory pain (Cao and Zhang, 2008; Ji et al., 2013). However, in bone cancer pain models, there is a large variation in spinal glial reaction, especially microglial reaction, due to differences in animal species/strains and sexes, and the origins of tumor cells. Despite a recent report from Ducourneau et al. (2014) showing no increases in glial markers, including GFAP, $\mathrm{S} 100 \beta$, and CD11b, in a bone cancer pain model induced by MRMT-1 cells in female SD rats, GFAP upregulation and astrogliosis have been frequently demonstrated in a vast majority of rat and mouse bone cancer models (Schwei et al., 1999; Honore et al., 2000; Medhurst et al., 2002; Zhang et al., 2005; Hald et al., 2009; Mao-Ying et al., 2012). Notably, microglial reaction is less evident in mouse bone cancer models in both sexes (Schwei et al., 1999; Hansen et al., 2011), while microglial activation is detected in male rats after inoculation of prostate cancer cells (Zhang et al., 2005) and in female rats after Walker 256 inoculation (Mao-Ying et al., 2012).

Our previous studies (Shan et al., 2007) showed an early $(<1$ d) microglial activation on the spinal dorsal horn after complete 

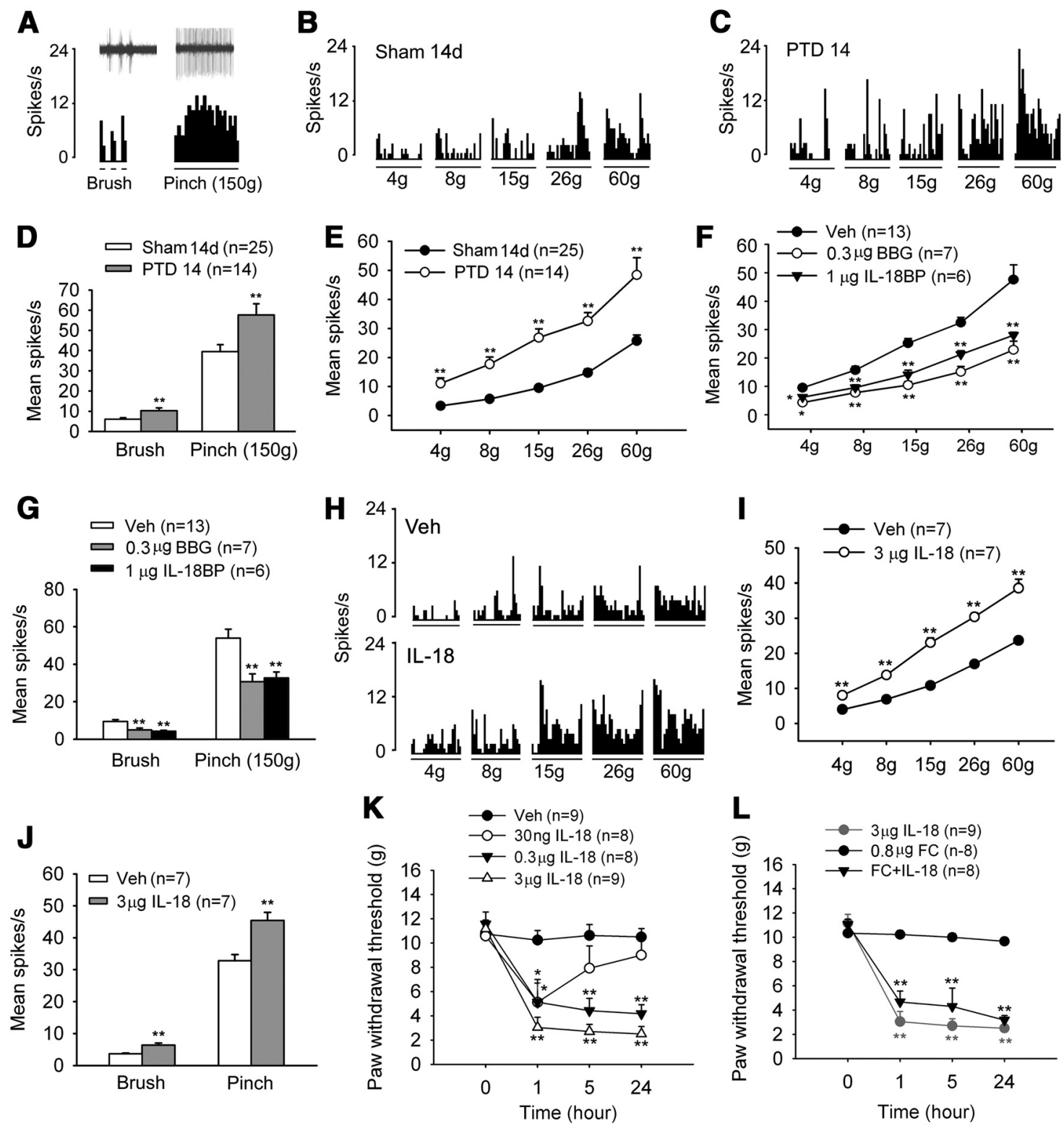

Figure 8. P2X7R/L-18 signaling regulates neuronal activity in the spinal dorsal horn. $A$, Histograms show typical responses of a WDR neuron to brush and pinch delivered to the receptive fields in a PTD 14 rat. Oscilloscope recording shows a single sweep (inset). $\boldsymbol{B}, C$, Histograms show the typical responses of WDR neurons to von Frey filament stimuli delivered to the receptive fields in a naive rat $(\boldsymbol{B})$ and a PTD 14 rat $(\boldsymbol{C})$. D, $\boldsymbol{E}$, The average number of discharges evoked by brush and pinch $(\boldsymbol{D})$ and von Frey hairs $(\boldsymbol{E})$ in PTD 14 rats is significantly higher than in sham rats. ${ }^{* *} p<0.01$ versus sham controls. $\boldsymbol{F}, \mathbf{G}$, Blockade of P2X7R by BBG or the inhibition of IL-18 by IL-18BP significantly suppresses the evoked responses of WDR neurons by von Frey hairs $(\boldsymbol{F})$, and brush and pinch $(\boldsymbol{G})$ stimuli in PTD 14 rats. ${ }^{*} p<0.05,{ }^{* *} p<0.01$ versus vehicle (Veh) control. $\boldsymbol{H}$, Histograms show the facilitatory effect of IL-18 on responses of WDR neurons to von Frey stimuli delivered to the receptive fields in a naive rats. $I, J$, Intrathecal injection of exogenous IL-18 $(3 \mu \mathrm{g})$ enhances the evoked response of WDR neurons by von Frey hairs $(\boldsymbol{I})$, and brush and pinch $(\boldsymbol{J})$ stimuli in naive rats. $\boldsymbol{K}$, Intrathecal injection of IL-18 of different doses $(0.03,0.3$, and $3 \mu \mathrm{g})$ induces allodynia in naive rats. L, Pretreatment of fluorocitrate (FC; $0.8 \mu \mathrm{g}=1 \mathrm{nmol}$, i.t., 30 min before IL- 18 injection) did not block IL-18-induced allodynia. ${ }^{*} p<0.05,{ }^{* *} p<0.01$ versus vehicle control.

Freund's adjuvant-induced monoarthritis, which is associated with the development of behavioral hypersensitivity. Instead, the upregulation of GFAP expression in the spinal dorsal horn was delayed by $3 \mathrm{~d}$ (Sun et al., 2008). A similar observation was also reported after peripheral nerve injury or spinal cord injury (Milligan et al., 2003; Raghavendra et al., 2003; Tanga et al., 2004; Ledeboer et al., 2005). Minocycline has also been shown to prevent the development of allodynia and hyperalgesia, but its role in reducing the established neuropathic and inflammatory pain is limited (Raghavendra et al., 2003; Ledeboer et al., 2005; Shan et al., 2007). Thus, spinal microglial and astrocytic activation may play a distinct role in inducing and maintaining neuropathic and inflammatory pain. Unexpectedly, the present study in a female
Wistar rat bone cancer pain model showed microglial activation at days 14 and 21, but not at day 7, whereas it showed astroglial activation at days 7, 14, and 21 after tumor inoculation. Moreover, intrathecal pretreatment of minocycline failed to prevent the development of bone cancer-induced allodynia and hyperalgesia. But post-treatment with minocycline effectively reduced cancer pain in the advanced phase. These results suggest a unique glial reaction process in bone cancer pain in female rats. Bone cancer-induced astrocytic activation can take place in a microglial activityindependent manner, though microglial activation may also lead to secondary astrogliosis in the advanced phase. Actually, a link between neuronal activity and astrocytic activation has been proposed by several groups (Steward et al., 1991; Xie et al., 2009). 
A

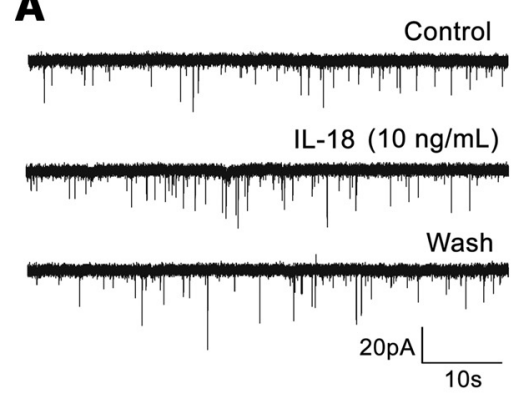

B

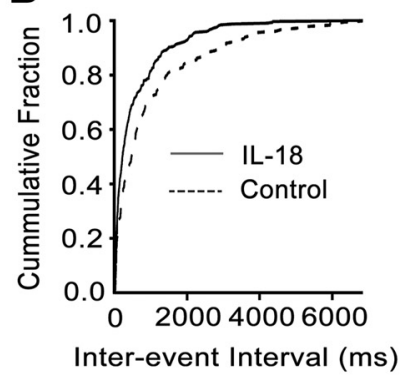

C

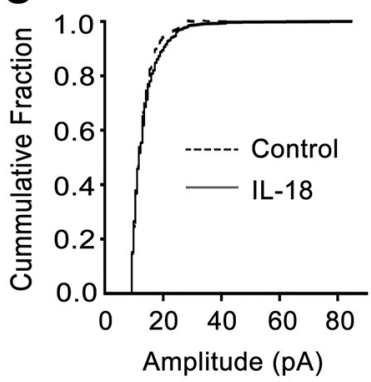

D

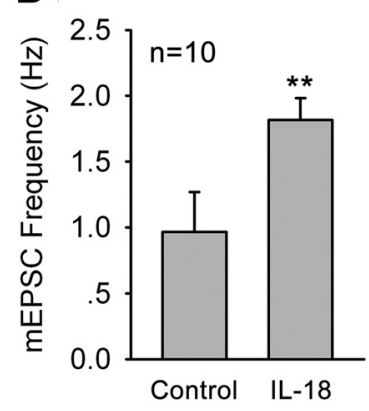

G

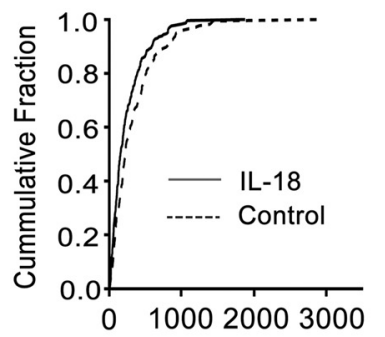

Inter-event Interval (ms)
E

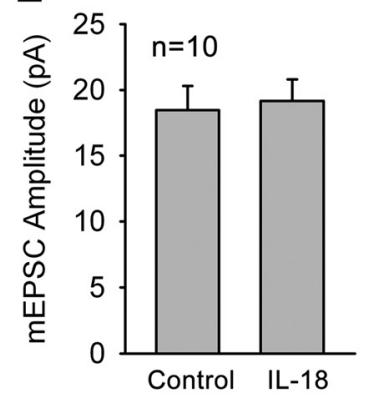

H

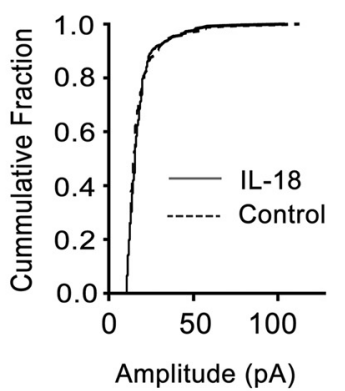

F

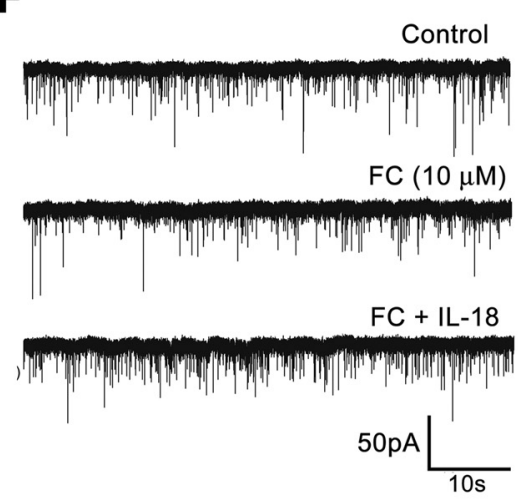

|

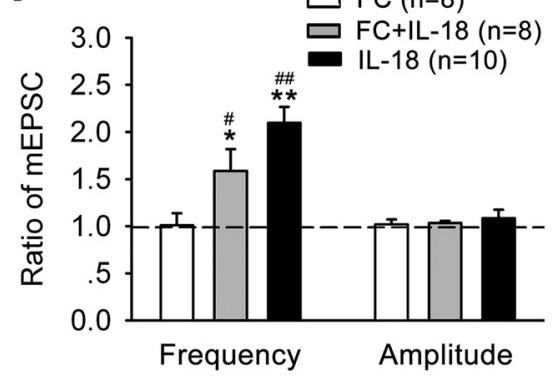

Figure 9. IL-18 modulates $\mathrm{mEPSC}$ in the superficial dorsal horn neurons. $\boldsymbol{A}$, Patch-clamp recording of $\mathrm{mEPSC}$ shows an increase in the frequency of $\mathrm{mEPSC}$ after perfusion of IL-18 (10 $\mathrm{ng} / \mathrm{ml}$ ). $\boldsymbol{B}, \boldsymbol{C}$, Corresponding cumulative distributions. $\boldsymbol{D}$, Quantification of mEPSC frequency. $\boldsymbol{E}$, Quantification of mEPSC amplitudes. ${ }^{* *} p<0.01$ versus control. $\boldsymbol{F}$, mEPSC traces show an increase in the frequency of mEPSCs after the perfusion of IL-18 in the presence of fluorocitrate (FC; $10 \mu \mathrm{M}$ ). $\mathbf{G}, \boldsymbol{H}$, Corresponding cumulative distributions. $\boldsymbol{I}$, Ratio of the frequency and amplitude of mEPSCs following treatment with IL-18, FC, and FC plus IL-18. Dashed line indicates baseline. Rats were pretreated with FC for 30 min before the application of IL-18. ${ }^{*} p<0.05$, ${ }^{* *} p<0.01$ versus control; $\# p<0.05$, \#\#p $<0.01$ versus $F C$ alone.

\section{P2X7R-mediated IL-18 upregulation in spinal microglia maintains bone cancer pain}

It is well established that microglial activation drives astrocytic activation (Raghavendra et al., 2003; Gao et al., 2009). On the other hand, astrocytes can also release signaling molecules to activate microglia. For example, after spinal cord injury, Cx43 upregulation results in the release of ATP (Kang et al., 2008), leading to microglial activation via $\mathrm{P} 2 \mathrm{X} 4 / \mathrm{P} 2 \mathrm{X} 7$ and $\mathrm{P} 2 \mathrm{Y} 6 / \mathrm{P} 2 \mathrm{Y} 12$ receptors (Tsuda et al., 2010; Trang et al., 2012). P2X7Rs are abundantly expressed in microglia, and play a pivotal role in the cross talk between microglia and neurons (Clark et al., 2010). The previous studies from our and other laboratories showed that blockade of P2X7Rs reduced nerve injury-induced spontaneous firing and evoked activity of spinal neurons (McGaraughty et al., 2007), and inhibited chronic morphine-induced enhancement of spontaneous EPSC frequency (Chen et al., 2012). In the present study, we further demonstrated P2X7R upregulation in spinal microglia following bone cancer. Knockdown of P2X7R inhibited bone cancer-induced IBA-1 upregulation and behavioral hypersensitivity, and suppressed bone cancer-induced hyperactivities of spinal WDR neurons. Despite previous reports that P2X7R is expressed by microglia (Tsuda et al., 2003; Zhou et al., 2010; Kobayashi et al., 2011), we also found disseminated P2X7R/GFAP double-labeled cells in the spinal dorsal horn from bone cancer rats. A similar observation was also reported in rats with incision pain (Ying et al., 2014). Moreover, P2X7R activation in cortical or spinal astrocytes was shown to release glutamate and ATP (Duan et al., 2003; Suadicani et al., 2006; Jarvis, 2010). Therefore, P2X7Rs may also be partially involved in regulating astrocyte signaling in the advanced phase of bone cancer pain.

Increasing evidence has suggested that microglial P2X7R modulates the release of proinflammatory cytokines (Hide et al., 2000; Clark et al., 2010), which have been shown to augment the nociceptive transmission in the spinal cord (Chessell et al., 2005; Zhang et al., 2011) via modulating excitatory and inhibitory synaptic transmission. IL-18 is a member of the IL- 1 family (Boraschi and Dinarello, 2006). IL-18 release can also be modulated by P2X7R and be involved in pathological pain (Verri et al., 2007; 


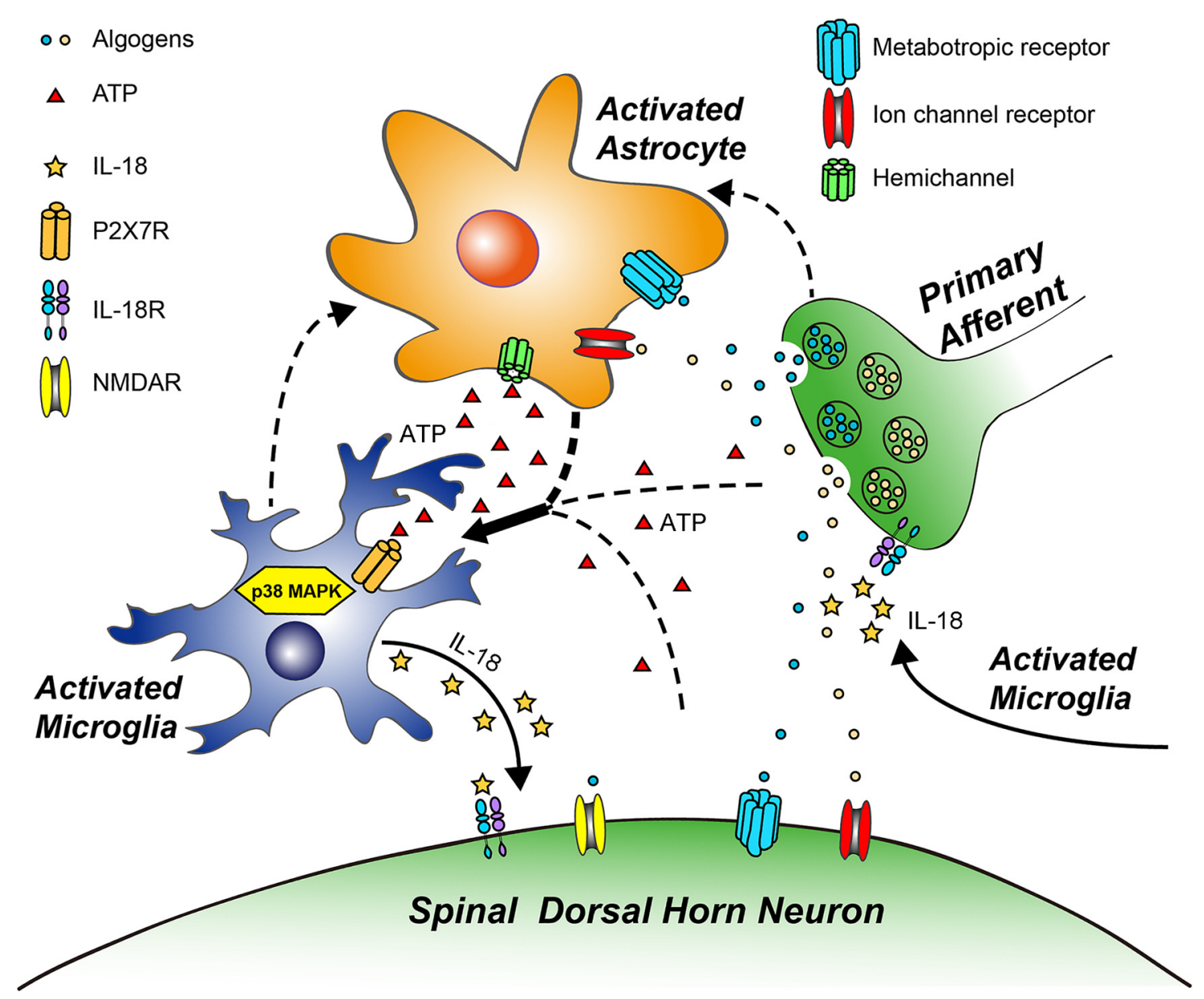

Figure 10. Schematic illustration of neuron- glia and glia-glia interactions in the spinal cord dorsal horn in bone cancer pain. Bone cancer-induced hyperexcitability of primary sensory neurons (peripheral sensitization) causes excessive release of neurotransmitters or neuromodulators from central afferent terminals to activate adjacent glia and postsynaptic neurons in the spinal dorsal horn. P2X7R is upregulated in microglia and activated by ATP, which is produced by activated astrocytes, as well as by primary afferent terminals and spinal cord neurons. Upon activation, microglia synthesize and release IL-18 via phosphorylation of $\mathrm{p} 38 \mathrm{MAPK}$, leading to enhanced excitatory synaptic transmission and neuronal hyperactivity in the dorsal horn (central sensitization). As a result of this IL-18-mediated neuromodulation in the spinal cord pain circuit, pain sensitivity is enhanced. Solid lines indicate the pathways and mechanisms demonstrated in this study. Dashed lines indicate other possible pathways and mechanisms.

Miyoshi et al., 2008). Activation of p38 MAPK, a transducer of various extracellular stimuli, induces the synthesis and release of proinflammatory cytokines, including IL-18 (Miyoshi et al., 2008). Activation of P2X7R increases the phosphorylation of $\mathrm{p} 38$ (Solle et al., 2001; Papp et al., 2007). The inhibition of spinal P2X7R blocks the upregulation of $\mathrm{p}-\mathrm{p} 38$ induced by neuropathic pain (Chu et al., 2010) and morphine tolerance (Zhou et al., 2010). These findings suggest that spinal microglia p38 can be activated by ATP via P2X7R, leading to the synthesis and release of microglial IL-18 and cancer pain (Fig. 10).

IL-18 mediates a variety of effects by interacting with its heterodimer receptor (IL-18R; Sergi and Penttila, 2004). IL-18R is expressed in neurons throughout the brain (Alboni et al., 2009). The application of IL-18 to hippocampal slices increases frequency and amplitude of mEPSCs in CA1 neurons (Kanno et al., 2004). Consistently, our data demonstrated that IL-18 rapidly (within $2 \mathrm{~min}$ ) increased the frequency of mEPSCs in spinal IIo neurons, suggesting that IL-18 can enhance presynaptic glutamate release. IIo neurons (predominantly excitatory ones) form a spinal cord pain circuit by receiving C-fiber input and making synapses with lamina I projection neurons (Todd, 2010), and they play an important role in chronic pain sensitization (Chen et al., 2014). Moreover, intrathecal injection of IL-18 significantly increased mechanically evoked responses of spinal WDR neurons in vivo, and also induced allodynia and hyperalgesia in naive rats.

In the spinal dorsal horn, IL-18R is also expressed in astrocytes and is responsible for astrocyte activation after nerve injury (Miyoshi et al., 2008; Chen et al., 2012; Bian et al., 2014). However, given the rapid effects of IL-18 on WDR neurons $(<30 \mathrm{~min}$ in intact spinal cord) and mEPSC frequency $(<2 \mathrm{~min}$ in spinal cord slices), microglia-derived IL-18 is likely to act directly on primary afferent terminals or dorsal horn neurons for facilitating nociceptive responses. Consistently, the IL-18-induced increase in mEPSCs was not affected by the glial metabolic inhibitor fluorocitrate.

\section{Conclusions and clinical relevance}

Chronic pain is emerging as a major health problem in the world, affecting $20 \%$ of the general population. Chronic pain conditions are not evenly distributed between the sexes, occurring more frequently in women (Mogil and Chanda, 2005; Mogil, 2012). Despite the increased incidence in women and the fact that clinical trials must incorporate woman into the trial design, current basic science research, including research on glial cells, focuses primarily on male subjects. Recent studies (Sorge et al., 2011) have demonstrated a clear gender difference in Toll-like receptor 
4 signaling at the level of the spinal cord. A very recent study (Vacca et al., 2014) has shown that spinal cord microglial and astroglial activation is enhanced in female animals in the late phase of nerve injury (121 d), but not in the early phase (7d). Our findings demonstrated a critical role of microglial activation in the maintenance, but not the induction, of cancer pain in female rats, which is in sharp contrast to the studies showing a predominant role of microglia in the induction of chronic pain in male animals. Thus, future studies are warranted to investigate microglia signaling not only in different phases, but also in different sexes.

\section{References}

Alboni S, Cervia D, Ross B, Montanari C, Gonzalez AS, Sanchez-Alavez M, Marcondes MC, De Vries D, Sugama S, Brunello N, Blom J, Tascedda F, Conti B (2009) Mapping of the full length and the truncated interleukin-18 receptor alpha in the mouse brain. J Neuroimmunol 214: 43-54. CrossRef Medline

Alboni S, Cervia D, Sugama S, Conti B (2010) Interleukin 18 in the CNS. J Neuroinflamm 7:9. CrossRef Medline

Bian C, Wang ZC, Yang JL, Lu N, Zhao ZQ, Zhang YQ (2014) Upregulation of interleukin-23 induces persistent allodynia via CX3CL1 and interleukin-18 signaling in the rat spinal cord after tetanic sciatic stimulation. Brain Behav Immun 37:220-230. CrossRef Medline

Boraschi D, Dinarello CA (2006) IL-18 in autoimmunity: review. Eur Cytokine Netw 17:224-252. Medline

Cao H, Zhang YQ (2008) Spinal glial activation contributes to pathological pain states. Neurosci Biobehav Rev 32:972-983. CrossRef Medline

Chen G, Park CK, Xie RG, Berta T, Nedergaard M, Ji RR (2014) Connexin-43 induces chemokine release from spinal cord astrocytes to maintain late-phase neuropathic pain in mice. Brain 137:2193-2209. CrossRef Medline

Chen ML, Cao H, Chu YX, Cheng LZ, Liang LL, Zhang YQ, Zhao ZQ (2012) Role of P2X7 receptor-mediated IL-18/IL-18R signaling in morphine tolerance: multiple glial-neuronal dialogues in the rat spinal cord. J Pain 13:945-958. CrossRef Medline

Chessell IP, Hatcher JP, Bountra C, Michel AD, Hughes JP, Green P, Egerton J, Murfin M, Richardson J, Peck WL, Grahames CB, Casula MA, Yiangou Y, Birch R, Anand P, Buell GN (2005) Disruption of the P2X7 purinoceptor gene abolishes chronic inflammatory and neuropathic pain. Pain 114:386-396. CrossRef Medline

Chu YX, Zhang Y, Zhang YQ, Zhao ZQ (2010) Involvement of microglial $\mathrm{P} 2 \mathrm{X} 7$ receptors and downstream signaling pathways in long-term potentiation of spinal nociceptive responses. Brain Behav Immun 24:11761189. CrossRef Medline

Clark AK, Staniland AA, Marchand F, Kaan TK, McMahon SB, Malcangio M (2010) P2X7-dependent release of interleukin- $1 \beta$ and nociception in the spinal cord following lipopolysaccharide. J Neurosci 30:573-582. CrossRef Medline

Colvin L, Fallon M (2008) Challenges in cancer pain management-bone pain. Eur J Cancer 44:1083-1090. CrossRef Medline

Duan KZ, Xu Q, Zhang XM, Zhao ZQ, Mei YA, Zhang YQ (2012) Targeting A-type $\mathrm{K}(+)$ channels in primary sensory neurons for bone cancer pain in a rat model. Pain 153:562-574. CrossRef Medline

Duan S, Anderson CM, Keung EC, Chen Y, Chen Y, Swanson RA (2003) $\mathrm{P} 2 \mathrm{X} 7$ receptor-mediated release of excitatory amino acids from astrocytes. J Neurosci 23:1320-1328. Medline

Ducourneau VR, Dolique T, Hachem-Delaunay S, Miraucourt LS, Amadio A, Blaszczyk L, Jacquot F, Ly J, Devoize L, Oliet SH, Dallel R, Mothet JP, Nagy F, Fénelon VS, Voisin DL (2014) Cancer pain is not necessarily correlated with spinal overexpression of reactive glia markers. Pain 155: 275-291. CrossRef Medline

Esmaeili MH, Movahedi M, Faraji A, Haghdoost-Yazdi H (2012) Intracerebral injection of low amounts of norharman induces moderate Parkinsonism-like behavioral symptoms in rat. Neurotoxicol Teratol 34: 489-494. CrossRef Medline

Gao YJ, Zhang L, Samad OA, Suter MR, Yasuhiko K, Xu ZZ, Park JY, Lind AL, Ma Q, Ji RR (2009) JNK-induced MCP-1 production in spinal cord astrocytes contributes to central sensitization and neuropathic pain. J Neurosci 29:4096-4108. CrossRef Medline

Hald A, Nedergaard S, Hansen RR, Ding M, Heegaard AM (2009) Differen- tial activation of spinal cord glial cells in murine models of neuropathic and cancer pain. Eur J Pain 13:138-145. CrossRef Medline

Hansen RR, Nielsen CK, Nasser A, Thomsen SI, Eghorn LF, Pham Y, Schulenburg C, Syberg S, Ding M, Stojilkovic SS, Jorgensen NR, Heegaard AM (2011) P2X7 receptor-deficient mice are susceptible to bone cancer pain. Pain 152:1766-1776. CrossRef Medline

He WJ, Cui J, Du L, Zhao YD, Burnstock G, Zhou HD, Ruan HZ (2012) Spinal P2X(7) receptor mediates microglia activation-induced neuropathic pain in the sciatic nerve injury rat model. Behav Brain Res 226:163170. CrossRef Medline

Hide I, Tanaka M, Inoue A, Nakajima K, Kohsaka S, Inoue K, Nakata Y (2000) Extracellular ATP triggers tumor necrosis factor-alpha release from rat microglia. J Neurochem 75:965-972. Medline

Honore P, Luger NM, Sabino MA, Schwei MJ, Rogers SD, Mach DB, O’keefe PF, Ramnaraine ML, Clohisy DR, Mantyh PW (2000) Osteoprotegerin blocks bone cancer-induced skeletal destruction, skeletal pain and painrelated neurochemical reorganization of the spinal cord. Nat Med 6:521528. CrossRef Medline

Imoto A, Mitsunaga S, Inagaki M, Aoyagi K, Sasaki H, Ikeda M, Nakachi K, Higuchi K, Ochiai A (2012) Neural invasion induces cachexia via astrocytic activation of neural route in pancreatic cancer. Int J Cancer 131: 2795-2807. CrossRef Medline

Inoue K (2007) P2 receptors and chronic pain. Purinergic Signal 3:135-144. CrossRef Medline

Jarvis MF (2010) The neural-glial purinergic receptor ensemble in chronic pain states. Trends Neurosci 33:48-57. CrossRef Medline

Ji RR, Berta T, Nedergaard M (2013) Glia and pain: is chronic pain a gliopathy? Pain 154 [Suppl 1]:S10-S28. CrossRef Medline

Kang J, Kang N, Lovatt D, Torres A, Zhao Z, Lin J, Nedergaard M (2008) Connexin 43 hemichannels are permeable to ATP. J Neurosci 28:47024711. CrossRef Medline

Kanno T, Nagata T, Yamamoto S, Okamura H, Nishizaki T (2004) Interleukin-18 stimulates synaptically released glutamate and enhances postsynaptic AMPA receptor responses in the CA1 region of mouse hippocampal slices. Brain Res 1012:190-193. CrossRef Medline

Kawasaki Y, Xu ZZ, Wang X, Park JY, Zhuang ZY, Tan PH, Gao YJ, Roy K, Corfas G, Lo EH, Ji RR (2008) Distinct roles of matrix metalloproteases in the early- and late-phase development of neuropathic pain. Nat Med 14:331-336. CrossRef Medline

Kobayashi K, Takahashi E, Miyagawa Y, Yamanaka H, Noguchi K (2011) Induction of the $\mathrm{P} 2 \mathrm{X} 7$ receptor in spinal microglia in a neuropathic pain model. Neurosci Lett 504:57-61. CrossRef Medline

Ledeboer A, Sloane EM, Milligan ED, Frank MG, Mahony JH, Maier SF, Watkins LR (2005) Minocycline attenuates mechanical allodynia and proinflammatory cytokine expression in rat models of pain facilitation. Pain 115:71-83. CrossRef Medline

Lü N, Han M, Yang ZL, Wang YQ, Wu GC, Zhang YQ (2010) Nociceptin/ Orphanin FQ in PAG modulates the release of amino acids, serotonin and norepinephrine in the rostral ventromedial medulla and spinal cord in rats. Pain 148:414-425. CrossRef Medline

Mantyh PW (2006) Cancer pain and its impact on diagnosis, survival and quality of life. Nat Rev Neurosci 7:797-809. CrossRef Medline

Mao-Ying QL, Wang XW, Yang CJ, Li X, Mi WL, Wu GC, Wang YQ (2012) Robust spinal neuroinflammation mediates mechanical allodynia in Walker 256 induced bone cancer rats. Mol Brain 5:16. CrossRef Medline

McGaraughty S, Chu KL, Namovic MT, Donnelly-Roberts DL, Harris RR, Zhang XF, Shieh CC, Wismer CT, Zhu CZ, Gauvin DM, Fabiyi AC, Honore P, Gregg RJ, Kort ME, Nelson DW, Carroll WA, Marsh K, Faltynek CR, Jarvis MF (2007) P2X7-related modulation of pathological nociception in rats. Neuroscience 146:1817-1828. CrossRef Medline

Medhurst SJ, Walker K, Bowes M, Kidd BL, Glatt M, Muller M, Hattenberger M, Vaxelaire J, O'Reilly T, Wotherspoon G, Winter J, Green J, Urban L (2002) A rat model of bone cancer pain. Pain 96:129-140. CrossRef Medline

Milligan ED, Twining C, Chacur M, Biedenkapp J, O’Connor K, Poole S, Tracey K, Martin D, Maier SF, Watkins LR (2003) Spinal glia and proinflammatory cytokines mediate mirror-image neuropathic pain in rats. J Neurosci 23:1026-1040. Medline

Miyoshi K, Obata K, Kondo T, Okamura H, Noguchi K (2008) Interleukin18-mediated microglia/astrocyte interaction in the spinal cord enhances neuropathic pain processing after nerve injury. J Neurosci 28:1277512787. CrossRef Medline 
Mogil JS (2012) Sex differences in pain and pain inhibition: multiple explanations of a controversial phenomenon. Nat Rev Neurosci 13:859-866. CrossRef Medline

Mogil JS, Chanda ML (2005) The case for the inclusion of female subjects in basic science studies of pain. Pain 117:1-5. CrossRef Medline

Papp L, Vizi ES, Sperlágh B (2007) P2X7 receptor mediated phosphorylation of p38MAP kinase in the hippocampus. Biochem Biophys Res Commun 355:568-574. CrossRef Medline

Raghavendra V, Tanga F, DeLeo JA (2003) Inhibition of microglial activation attenuates the development but not existing hypersensitivity in a rat model of neuropathy. J Pharmacol Exp Ther 306:624-630. CrossRef Medline

Schwei MJ, Honore P, Rogers SD, Salak-Johnson JL, Finke MP, Ramnaraine ML, Clohisy DR, Mantyh PW (1999) Neurochemical and cellular reorganization of the spinal cord in a murine model of bone cancer pain. J Neurosci 19:10886-10897. Medline

Sergi B, Penttila I (2004) Interleukin 18 receptor. J Biol Regul Homeost Agents 18:55-61. Medline

Shan S, Qi-Liang MY, Hong C, Tingting L, Mei H, Haili P, Yan-Qing W, Zhi-Qi Z, Yu-Qiu Z (2007) Is functional state of spinal microglia involved in the anti-allodynic and anti-hyperalgesic effects of electroacupuncture in rat model of monoarthritis? Neurobiol Dis 26:558-568. CrossRef Medline

Shi Y, Gelman BB, Lisinicchia JG, Tang SJ (2012) Chronic-pain-associated astrocytic reaction in the spinal cord dorsal horn of human immunodeficiency virus-infected patients. J Neurosci 32:10833-10840. CrossRef Medline

Solle M, Labasi J, Perregaux DG, Stam E, Petrushova N, Koller BH, Griffiths RJ, Gabel CA (2001) Altered cytokine production in mice lacking P2X(7) receptors. J Biol Chem 276:125-132. CrossRef Medline

Sorge RE, LaCroix-Fralish ML, Tuttle AH, Sotocinal SG, Austin JS, Ritchie J, Chanda ML, Graham AC, Topham L, Beggs S, Salter MW, Mogil JS (2011) Spinal cord Toll-like receptor 4 mediates inflammatory and neuropathic hypersensitivity in male but not female mice. J Neurosci 31 : 15450-15454. CrossRef Medline

Steward O, Torre ER, Tomasulo R, Lothman E (1991) Neuronal activity up-regulates astroglial gene expression. Proc Natl Acad Sci U S A 88: 6819-6823. CrossRef Medline

Suadicani SO, Brosnan CF, Scemes E (2006) P2X7 receptors mediate ATP release and amplification of astrocytic intercellular $\mathrm{Ca}^{2+}$ signaling. J Neurosci 26:1378-1385. CrossRef Medline

Sun S, Cao H, Han M, Li TT, Zhao ZQ, Zhang YQ (2008) Evidence for suppression of electroacupuncture on spinal glial activation and behavioral hypersensitivity in a rat model of monoarthritis. Brain Res Bull 75:83-93. CrossRef Medline

Suter MR, Wen YR, Decosterd I, Ji RR (2007) Do glial cells control pain? Neuron Glia Biol 3:255-268. CrossRef Medline

Tanga FY, Raghavendra V, DeLeo JA (2004) Quantitative real-time RTPCR assessment of spinal microglial and astrocytic activation markers in a rat model of neuropathic pain. Neurochem Int 45:397-407. CrossRef Medline
Todd AJ (2010) Neuronal circuitry for pain processing in the dorsal horn. Nat Rev Neurosci 11:823-836. CrossRef Medline

Trang T, Beggs S, Wan X, Salter MW (2009) P2X4-receptor-mediated synthesis and release of brain-derived neurotrophic factorin microglia is dependent on calcium and p38-mitogen-activated protein kinase activation. J Neurosci 29:3518-3528. CrossRef Medline

Trang T, Beggs S, Salter MW (2012) ATP receptors gate microglia signaling in neuropathic pain. Exp Neurol 234:354-361. CrossRef Medline

Tsuda M, Shigemoto-Mogami Y, Koizumi S, Mizokoshi A, Kohsaka S, Salter MW, Inoue K (2003) P2X4 receptors induced in spinal microglia gate tactile allodynia after nerve injury. Nature 424:778-783. CrossRef Medline

Tsuda M, Tozaki-Saitoh H, Inoue K (2010) Pain and purinergic signaling. Brain Res Rev 63:222-232. CrossRef Medline

Vacca V, Marinelli S, Pieroni L, Urbani A, Luvisetto S, Pavone F (2014) Higher pain perception and lack of recovery from neuropathic pain in females: a behavioural, immunohistochemical, and proteomic investigation on sex-related differences in mice. Pain 155:388-402. CrossRef Medline

Verri WA Jr, Cunha TM, Parada CA, Poole S, Liew FY, Ferreira SH, Cunha FQ (2007) Antigen-induced inflammatory mechanical hypernociception in mice is mediated by IL-18. Brain Behav Immun 21:535-543. CrossRef Medline

Xie W, Strong JA, Zhang JM (2009) Early blockade of injured primary sensory afferents reduces glial cell activation in two rat neuropathic pain models. Neuroscience 160:847-857. CrossRef Medline

Xu Q, Zhang XM, Duan KZ, Gu XY, Han M, Liu BL, Zhao ZQ, Zhang YQ (2013) Peripheral TGF- $\beta 1$ signaling is a critical event in bone cancerinduced hyperalgesia in rodents. J Neurosci 33:19099-19111. CrossRef Medline

Ying YL, Wei XH, Xu XB, She SZ, Zhou LJ, Lv J, Li D, Zheng B, Liu XG (2014) Over-expression of $\mathrm{P} 2 \mathrm{X} 7$ receptors in spinal glial cells contributes to the development of chronic postsurgicalpain induced by skin/muscle incision and retraction (SMIR) in rats. Exp Neurol 261:836-843. CrossRef Medline

Zhang L, Berta T, Xu ZZ, Liu T, Park JY, Ji RR (2011) TNF- $\alpha$ contributes to spinal cord synaptic plasticity and inflammatory pain: distinct role of TNF receptor subtypes 1 and 2. Pain 152:419-427. CrossRef Medline

Zhang RX, Liu B, Wang L, Ren K, Qiao JT, Berman BM, Lao L (2005) Spinal glial activation in a new rat model of bone cancer pain produced by prostate cancer cell inoculation of the tibia. Pain 118:125-136. CrossRef Medline

Zhang Y, Xiao X, Zhang XM, Zhao ZQ, Zhang YQ (2012) Estrogen facilitates spinal cord synaptic transmission via membrane-bound estrogen receptors: implications for pain hypersensitivity. J Biol Chem 287:3326833281. CrossRef Medline

Zhou D, Chen ML, Zhang YQ, Zhao ZQ (2010) Involvement of spinal microglial P2X7 receptor in generation of tolerance to morphine analgesia in rats. J Neurosci 30:8042-8047. CrossRef Medline 